Resumen por el autor, W. H. Taliaferro.

Universidad Johns Hopkins.

Reacciones de Planaria maculata a la acción de la luz, con especial mención de la función y estructura de los ojos.

1. El ojo de Planaria maculata consta de dos partes: las retínulas y las células accesorias que forman la copa pigmentaria. 2. Los ejemplares normales son negativos a la luz y se orientan exactamente en un rayo luminoso horizontal. 3. Los ejemplares con ambos ojos extirpados son negativos a la luz, pero no se orientan. 4. Los ejemplares con un ojo extirpado no exhiben movimientos circulares. Se orientan como los ejemplares normales cuando se les ilumina el lado normal, pero no se orientan cuando la iluminación se dirige al lado "ciego," a menos que se muevan hasta recibir la luz en el ojo funcional. 5. Las reacciones de los ejemplares con un ojo normal y la mitad posterior o anterior del otro ojo extirpada se describen en el trabajo. 6. La extirpación de los ojos, a diferencia de lo que sucede al cortar el extremo anterior, no produce efecto sobre la marcha de la locomoción en la luz directiva o no directiva. 7. El ojo consta de dos regiones sensoriales localizadas; la estimulación de una e ellas causa el movimiento del animal en un sentido opuesto al ocupado por el lado que contiene el ojo, mientras que la estimulación de la otra produce el efecto opuesto. 8. Aunque el pigmento puede localizar a la estimulación fótica en cierto grado, probablemente no es el principal agente localizador de la estimulación fótica, como ha indicado Hesse. 9. La localización del estímulo luminoso está relacionada con la estructura y posición de los rabdomas. 10. Una vez que el animal se orienta en un rayo luminoso horizontal no recibe estimulación orientadora hasta que abandona el eje de orientación.

Translation by José F. Nonidez

Cornell University Medical College, N. Y. 


\title{
REACTIONS TO LIGHT IN PLANARIA MACULATA," WITH SPECLAL REFERENCE TO THE FUNCTION AND STRUCTURE OF THE EYES
}

\author{
W. H. TALIAFERRO \\ Zoological Laboratory of the Johns Hopkins University \\ EIGHTEEN FIGURES
}

CONTENTS

Introduction.............................................6. 60

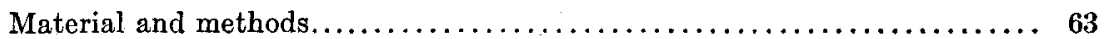

Structure of the eye...................................... 68

Orientation to light in normal specimens......................... 72

Orientation to a horizontal beam of light..................... 72

1. Extraneous reflexes during orientation.................. 74

2. Character of turning in animals during orientation in different intensities of illumination........................... 75

Function of the eyes........................................ 79

A. Reactions to light in specimens with both eyes removed........, 79

1. Character of reactions to light....................... 81

2. Rate of locomotion............................. 84

3. Discussion of experiments in relation to former investigations 86

B. Reactions to light in specimens with one eye removed........... 87

C. Localized sensory regions in the eye.......................... 93

1. Extent of localized sensory regions................... 93

2. Reactions to light in specimens with one eye and the posterior half of the other eye removed.................... 98

3 Reactions to light in specimens with one eye and the anterior half of the other eye removed.................... 101

D. Localization of photic stimulation ...................... 102

1. Mechanism of localization of photic stimulation ........... 102

2. Localization of photic stimulation in relation to the structure of the eye $\ldots \ldots \ldots \ldots \ldots \ldots \ldots \ldots \ldots \ldots \ldots \ldots \ldots \ldots, \ldots \ldots \ldots$

Nature of the stimulus during orientation $\ldots \ldots \ldots \ldots \ldots \ldots \ldots \ldots \ldots \ldots \ldots, 109$

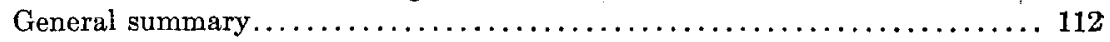

Bibliography $\ldots \ldots \ldots \ldots \ldots \ldots \ldots \ldots \ldots \ldots \ldots \ldots \ldots \ldots \ldots \ldots \ldots \ldots, 114$

1 Although there is some uncertainty as to the species of Planaria used in the experiments recorded in this paper, it has been designated maculata. This question is discussed on page 64 . 


\section{INTRODUCTION}

In the extensive literature on the Turbellaria one finds rather detailed and careful studies concerning both the structure of the eyes and the reactions to light in various forms. In very little of this work, however, is there any attempt to coördinate the known histological details of the eye with the reactions to light. The chief object of the present paper is to ascertain in how ar the function of the eyes in the reactions to light in Planaria maculata can be correlated with the histology of these organs.

One of the most important contributions to our knowledge of the turbellarian eye is Hesse's ('97) study of the structure of these organs. Hesse, working for the most part with certain triclads, found that all such eyes consist of two parts: first, the visual cells or retinulae, each of which possesses a typical nucleus and is extended distally to form a bulb-like rhabdome, and proximally to form a nerve process which enters the 'brain;' second, the pigment or accessory cells which form a more or less cup-shaped structure partially enclosing the rhabdomes or sensory area of the eye. He states that the number of retinulae, as well as of pigment cells, varies in different species from one to a large number. The triclads studied by Hesse were negative to light, and hence moved away from the source of stimulation. He maintains that this reaction is due to the fact that when an animal moves away from the light the sensory cells or rhabdomes are shaded by the pigment cup; whereas, when the specimen moves in any other direction the pigment cup does not shade all of the rhabdomes. When certain of the rhabdomes are illuminated, as in the latter case, the animal•turns so as to bring the sensory region of the eye again into the shadow of the pigment cup. Hesse maintains that localization of the photic stimulus is the specific function of the pigment cup which enables the animal to direct its course away from the source of light.

In working on the eye of the rhabdocoele, Prorhynchus applanatus, Kepner and Taliaferro ('16) found that it consisted of one retinula associated with a unicellular pigment cup or accessory cell. Although the relation of these two elements is 
exactly that found by Hesse ('97), they found that the retinula consists of three regions: 1) a lateral nucleus-bearing region which is closely applied to the 'brain' and extends as a nerve fiber into this organ; 2) a middle region which is lens-shaped and in both living and fixed material presents the structure of a highly refractive homogeneous body, and, 3) a mesial region or the true rhabdome which fills the pigment cup.

Kepner and Foshee ('17), in a further study of Prorhynchus applanatus, point out an interesting comparison between the three regions of the retinula in Prorhynchus and the retinula (rods and cones) of vertebrates. According to these authors, the nucleus-bearing region, the highly refractive region, and the rhabdome of Prorhynchus are analogous, if not indeed homologous with the myoid, ellipsoid, and rhabdome, respectively, in the rods and cones of the vertebrates. This comparison is especially interesting in that the retinula of both flatworms and vertebrates are of the inverted type.

Jänichen ('97) was probably the first to describe the middle region in the retinula of the turbellarian eye as a definite structure. He referred to it in Planaria gonocephala as the 'Zwischenstück,' but placed no emphasis upon.it. Böhmig ('90) T. xxi, fig. 12) figures much the same type of structure in the rhabdocoele Monoophorum striatum, but does not mention it in his description. Also, in the eye of the polyclad Pelmatoplana as figured by Schmidt ('02) there is a body very much like the one under consideration, but it is considered by that author to be a nucleus.

No attempt will be made to review in detail the literature of the reactions of the Turbellaria to light. Such a review may be found in Walter's ('07) paper. We shall, therefore, confine ourselves to certain papers dealing with the functions of the eye. The first paper treating this specific subject is that of Loeb ('94), who maintains that decapitated specimens of Planaria torva react to light in precisely the same manner as normal specimens, but that the reactions are slower. He found, however, that the removal of the 'brain' and eyes of the polyelad Thysanozoön brochii, unlike Planaria torva, caused the animals to lose their responsiveness to light. 
In the paper mentioned above, Hesse ('97) carried out similar experiments on Planaria gonocephala and obtained results which agreed with Loeb's work on Planaria torva, namely, that decapitated worms gave the same reactions to light as normal ones except that the reactions required more time.

Parker and Burnett ('00) made a much more comprehensive and thorough study of the same question, using more accurate methods and treating the results statistically. They used in their experiments Planaria gonocephala, and confirm in the main the results obtained by previous investigators both as regards the reactions of decapitated worms and the time required for such reactions.

In experiments on regeneration in Dendrocoelum lacteum, Lillie ('01) found, in harmony with the results obtained by Loeb in the polyclad Thysanozoön, that posterior headless pieces of this turbellarian do not react to light like normal specimens. He also maintains that any piece of a specimen of Dendrocoelum lacteum which is incapable of regeneration is, after a day or so, incapable of giving the normal responses to light.

Mast ('10), in a preliminary account of some experiments on a marine turbellarian, probably a triclad, found that these animals orient fairly precisely to a horizontal beam of light, but that they do not orient after the eyes have been removed by gouging them out with a scalpel.

From this short survey of the literature, we see that while the various descriptions of the structure of the turbellarian eye agree in all major details, the results of the work on the function of such eyes are so conflicting that it is almost impossible to draw any definite conclusions. The work of Loeb ('94) on Planaria torva, Hesse ('97) on Planaria gonocephala, and Parker and Burnett ('00) on the same form, indicates that the removal of the eyes affects the reactions to light very little except to make the reactions slower. Opposed to these results, the work of Loeb ('94) on Thysanozoön brochii, Lillie ('01) on Dendrocoelum lactum, and Mast ('10) on a marine form indicates that removal of the eyes results in the loss of the typical reactions to light. In all of this work, however, with the possible exception 
of Mast, the technique employed was very crude. With this one exception the method of removing the eyes was to remove the entire head. The results of the present paper make it very doubtful if conclusions regarding the functions of the eyes can be drawn from the study of decapitated specimens.

The plan of the present paper is, first, to make a careful histological and cytological study of the eye in Planaria maculata and, second, with this anatomical background, to ascertain, by much more precise technique than used previously, the part played by the eyes in the reactions to light. This necessitated a study of the normal reactions to light. Similarly it led to a study of the mechanies of orientation to light in specimens which had one or both eyes removed and of specimens having one eye and a portion of the other eye removed. It also led to a study of the function of the pigment.

It gives me great pleasure to acknowledge my indebtedness to Prof. S. O. Mast, under whom the work was done, and to Prof. W. A. Kepner, of the University of Virginia, who, besides following the work with great interest, tendered many helpful suggestions and criticisms. Much valuable assistance was also received from Miss M. L. Dinwiddie, of the University of Virginia. The author is indebted to Dr. S. R. Detwiler, of Yale University, for the photographs in figure 7 and to Miss B. E. Stocking for the drawing in figure 13.

\section{MATERIALS AND METHODS}

All of the experimental work in this paper was done on a planarian found in abundance in an abandoned ice-pond near the University of Virginia. Collections were made by bringing roots, leaves, and debris from the margin of the pond and placing them in large aquaria filled with tap water. In such aquaria specimens begin to rise to the top in a few hours. They can then readily be removed with a section lifter. Although most of the experiments were performed on animals which had been freshly collected, it was found that they could be reared in the laboratory by keeping them in fresh spring water and feeding about once a week with finely teased Tubifex. 
The planarian referred to above belongs to the genus Planaria, but as to the species there is some question, owing to the fact that the reproductive organs were not observed and that in these organs are found the chief characteristics which at prèsent determine the species. Specimens have been collected from the same locality, at irregular intervals, by Professor Kepner for nine years and by the author for five years. In spite of these repeated attempts, no sexually mature animals have been obtained. Moreover, specimens have been reared in the laboratory and kept under almost constant observation for nearly two years. During this period the animals reproduced solely by asexual fission.

In an earlier report of this work ('17) the planarian under consideration was considered a new species. At the present time, however, the writer is of the opinion that it is so closely related to Planaria maculata Leidy, that it may be considered a variety of this species. In shape, size, general color, and normal fission, it agrees very well with the description given by Woodward ('97) Curtis ('02), and Bardeen ('01) for Planaria maculata. In color it is, however, very much more variable than maculata, judging from the descriptions, of this species, extending from an almost gray through brown to almost black. There are also other respects in regard to which the specimens under consideration do not agree with the descriptions of Planaria maculata. Most prominent among these is the structure of the enteron. The descriptions indicate that the enteron of Planaria maculata has many anastomosing diverticula. In the planarian used in these experiments there are relatively few, certainly far fewer than are shown in the figures of Curtis ('02). There is also a marked difference in the reactions. The planarians used in this work oriented to light very much more precisely than did specimens which agree more closely with the description of Planaria maculata obtained from other localities.

In operating, three methods for quieting the worms were found useful; viz., lowering the temperature with a salt-and-ice mixture, adding a few crystals of chlorotone to the water, and treating the animals with carbon dioxide. Of these three methods, the 
last was used with the greatest success. A specimen to be operated on was placed under a binocular in a flat dish containing a layer of paraffin on the bottom. All of the water was then drawn from the specimen with a small pipette and the animal quickly covered with carbonated water from a siphon bottle ordinarily used in making carbonated drinks. In twenty to thirty seconds the animal thus treated usually becomes motionless. The carbonated water was then drawn off and the specimen operated on. As soon as the operation was complete, the planarian was removed and placed in a numbered aquarium filled with fresh spring water, where it was kept for observation. The practice of drawing off all of the water just before operating is essential, as it causes a secretion of mucus which holds the animal fairly fast to the substratum. This mucus adheres more strongly to paraffin than to such substances as glass.

The operations made consist largely of removing eyes, making incisions, and cutting off various parts of the body. The instrument used in making these operations consisted of a fine knife made by breaking a diagonal piece from a Gillette safetyrazor blade. This was then placed in a wooden handle and carefully ground on the back to a fine point. With careful manipulation one can run such a knife under the eye of a planarian and remove it without appreciably disturbing any of the surrounding tissue. Parts of an eye can even be removed without destroying the capacity to function of the remainder of the organ.

In making delicate operations upon planarians it was soon recognized that there was no way of accurately estimating the injury from the operation in the living specimen. For this reason each animal, after being experimented upon, was carefully fixed and sectioned to ascertain the extent of the injury to the various organs. In this as well as in the general histological work several fixing fluids were used, such as Flemming's stronger solution, Bouin's fluid, Worcester's fluid, and various corrosivesublimate mixtures. In practically all cases, however, the best results were obtained with a chromo-aceto-formalin mixture used by Kepner and Taliaferro ('16) in working with Rhabdocoeles. One very desirable characteristic of this fluid is that it kills so 
rapidly that no anesthetic is necessary to obtain animals fixed free from contortions. In the general histological work iron haematoxylin with Bordeaux red, and Mallory's connective-tissue stain were used. For ascertaining the amount of injury due to the operations, by far the most useful was Mallory's connectivetissue stain. For general purposes this stain was used almost exclusively.

The apparatus used for observing the orientation of animals in a horizontal beam of light was essentially like that used by Mast ('11) and a number of other investigators (fig. 1). The apparatus was so constructed that two horizontal beams of light intersected at right angles in the aquarium in which the observations were made. Either beam could be eliminated and the one eliminated could be changed almost instantly by means of a double-throw switch (fig. 1, K). Each beam of light was produced by a 125-watt gas-filled lamp (fig. 1, $L$ ) which was housed in a well-ventilated, light-tight box and properly screened. Each of these boxes was placed on a graduated track along which they could be moved. The distance of the light source and hence the intensity of illumination could thus be varied at will. Each beam of light after leaving the aperture in its box was passed through distilled water $(25 \mathrm{~mm}$.) to remove the heat-waves, and was then so screened as to permit practically nothing but parallel rays to strike the animals (fig. 1 ). The heat-waves were of course further absorbed by passing through the water of the aquarium in which the animals were placed. The stand on which the aquarium rested was of the same height as a microscope stage, so that in carefully observing the path of an animal a microscope with a camera-lucida attachment could be substituted for the stand. When a microscope with a camera lucida was used, a small drawing-board was placed beside the microscope (fig. 1, C.), and illuminated by a small light which was so secured that no light could strike the animals under observation. In tracing the paths of specimens with a microscope and camera lucida, it was found advisable to use very low magnifications. The use of very low objectives $\left(\frac{1}{2}\right.$ inch) and eyepieces not only permitted the observation of specimens over a greater range, but it also 
obviated the necessity of providing any vertical illumination for the microscope, the horizontal beam of light used in the experiment being quite sufficient. Had it been necessary to use verti-

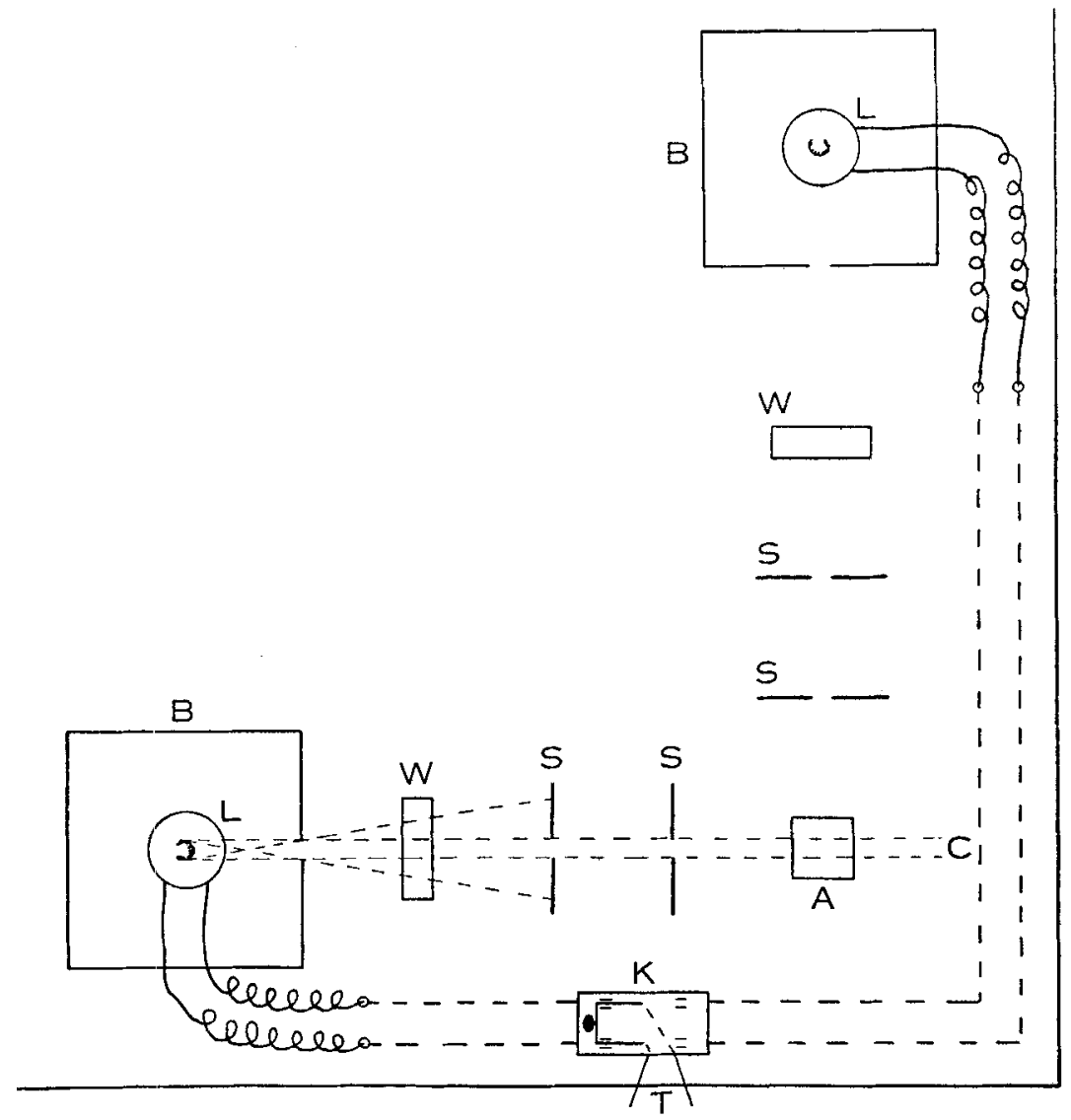

Fig. 1 Diagram of apparatus for observing reactions of Planaria to a horizontal beam of light. $A$, aquarium; $B$, lamp boxes which can be moved toward and away from the aquarium; $C$, position of drawing-board when camera-lucida is used; $K$, double-throw, double-pole knife switch; $L, 125$-Watt gas-filled lamp; $S$, screen; $T$, wires to wall tap; $W$, distilled water.

cal illumination, it might have introduced an extraneous factor in these experiments.

The aquaria in which the animals were observed were rectangular. They were made of plate glass and Kotinsky cement. 
The use of such aquaria is essential, as it is practically impossible to control the path of the rays of light after being refracted by the irregular curved sides of the ordinary aquarium. All observations were made in a dark room and, as far as possible, all apparatus was painted dull black so as not to reflect light.

The apparatus used for measuring the rate of movement in specimens was essentially like that of Walter ('07, p. 55). The animals were placed in an aquarium which was held a few inches above a table by means of a burette stand and clamp. A pantograph was then so arranged that the style on the tracing arm was directed upward and could be moved beneath the aquarium. Care was always taken not to allow the tracing style to come in contact with the aquarium, as the consequent jarring causes a disturbance in the reactions of the specimens. A pencil in the remaining arm of the pantograph was directed downward and placed in contact with a sheet of paper on the table. By means of the style, a given worm could be followed and the path recorded. All such paths were made at a magnification of two diameters to facilitate measuring. After the path of a specimen was recorded for a definite number of minutes it was measured with a chartometer. In this way the character as well as the length of the path was ascertained.

\section{STRUCTURE OF THE EYE}

According to all of the recent descriptions of the structure of the turbellarian eye, it contains two regions-a pigment-cup formed by the pigment or accessory cells and a sensory region composed of visual cells or retinulae. As has been previously stated, a careful study of the retinula has shown in at least one form, Prorhynchus applanatus, that it is composed of three regions - the nucleus-bearing portion, a central highly refractive lens-shaped portion, and the true sensory portion or rhabdome. These three regions bear a striking resemblance to the three regions of the rods and cones in the vertebrate eye, i.e., the myoid, ellipsoid, and rhabdome, respectively. The comparison is of especial interest in that the retinulae in both groups of animals 
are of the inverted type and, hence, the arrangement of the three regions in relation to the entrance of the stimulating light is the same.

The eyes of Planaria maculata appear as two small conspicuous dark spots on the anterior, dorsal surface of the animal near the median line. Each eye lies directly over, and near the anterior margin of a dorsal ganglion. The pigmented regions constitute the pigment-cups. The opening of each pigment-cup is directed laterally, anteriorly, and slightly dorsally. It is formed by a single layer of pigment or accessory cells (fig. 2, A). By referring to figure 2 , it may be seen that the pigment of the pigment-cup is in the form of granules and that these are represented as being concentrated at the inner surface of the accessory cells. It has, however, been repeatedly observed that these granules of pigment are concentrated at the inner surface of the pigment cell only after the animal has been exposed to long-continued illumination and that in darkness they tend to become scattered through the entire cell.

The cavity of the pigment-cup is filled with the distal end of numerous retinulae (fig. $2, R$ ). The number of these retinulae in any given eye has not been precisely ascertained, but it is approximately two hundred. Each retinula consists of three regions - a rhabdome, a central highly refractive region, and a nucleus-bearing portion (fig. 3, C). The rhabdome and central region constitute the portion of the retinula surrounded by the pigment cup. The nucleus-bearing portion is in reality a nervelike fiber which extends from the central region of the rhabdome through the opening of the pigment cup to the 'brain.' Some distance from the cup there is an enlargement in the fiber which contains the nucleus.

The three regions of the retinula are differentiated very distinctly in material stained with Mallory's connective-tissue stain. The rhabdome, which is situated next to the wall of the pigment cup, shows numerous radiating striae (fig. 2, S). The striae all radiate from the central region, which is a clear, more or less spherical body. This region (fig. $2, m$ ) stains bright orange, while the rest of the retinulae, with the exception of the nucleus, 
W. H. TALIAFERRO
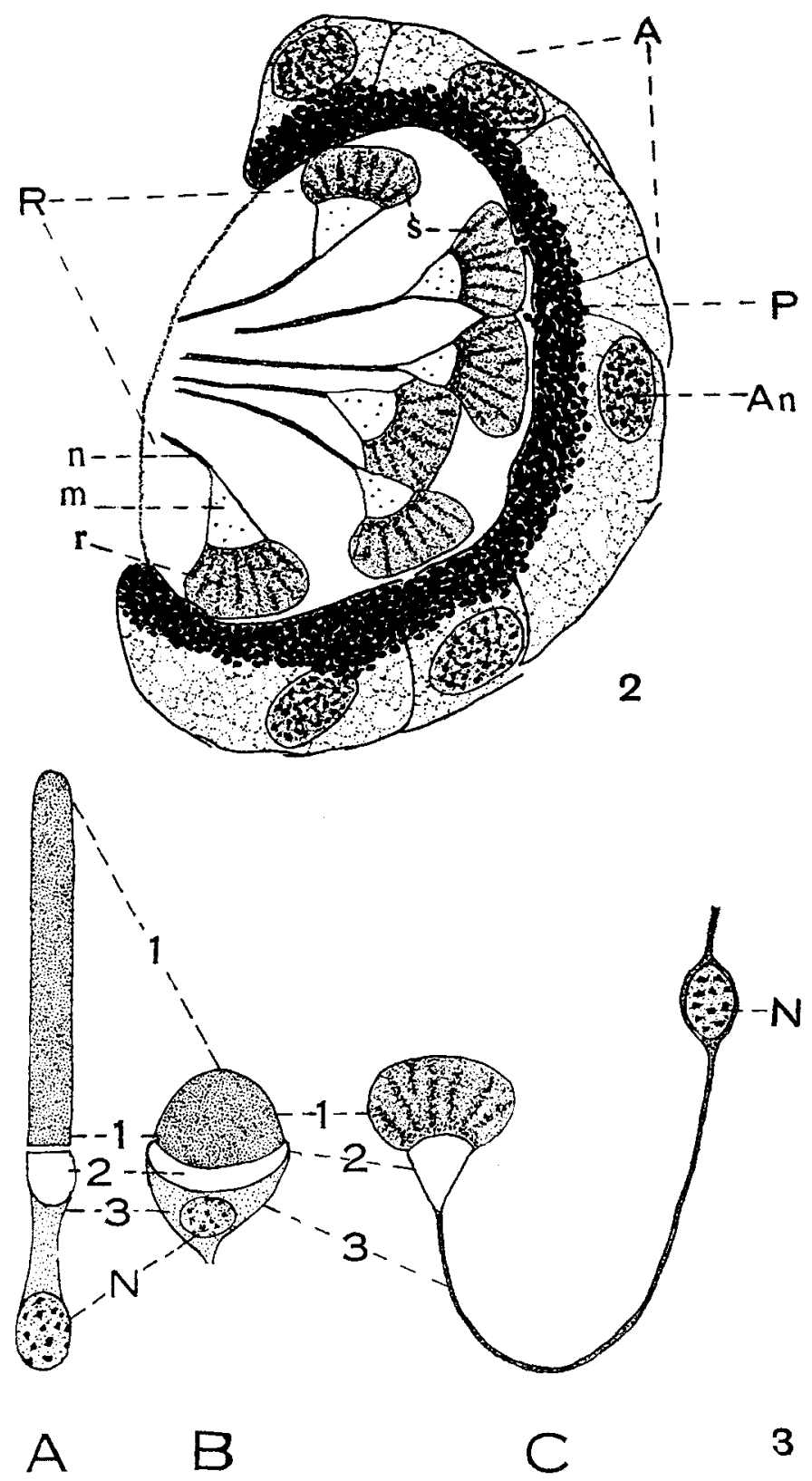
stains blue. In fixed material this region is optically the densest portion of the retinula. No special structure can be distinguished in the third or nucleus-bearing region except the nucleus. This is large and approximately spherical (fig. $3, C, N$ ). Its general appearance, as well as its staining reactions, indicates that it is a modified nerve element.

All of the fibers of the nucleus-bearing region issue from the pigment-cup at the anteriolateral margin of the opening. The position of these fibers was later found of great importance as any injury to the anterior part of the eye destroys the function of the entire organ by destroying them.

From this description it is evident that the retinula in Planaria maculata is very much like the retinula in Prorhynchus applanatus and the regions found in it are similar to the rhabdome, ellipsoid, and myoid of the vertebrate rods and cones, just as Kepner and Foshee ('17) maintain for Prorhynchus applanatus (fig. 3). A similar differentiation has been described by Kepner and Lawrence ('18) in the retinula of Polycystis goettei.

The discovery of this analogy or, possibly, homology of the parts of the retinula of the rhabdocoele eye with the parts of the vertebrate eye is very significant, for it strongly supports the contention of some observers that the simple chordate eyes of Branchiostoma are homologous with the flatworm eyes. It is, however, questionable whether organs of two groups of animals as far removed as are the Platyhelminthes and chordates can be homologized.

Fig. 2 Camera-lucida drawing of a transverse section of the eye of Planaria maculata. $\times 1500 . A$, accessory cells; $A n$, nucleus of accessory cell; $P$, pigment-cup containing visual cells or retinulae, some of which have been omitted; $R$, retinulae; $r$, rhabdome; $s$, striae in the rhabdome; $m$, middle region of the retinula; $n$, portion of the nucleus-bearing region of the retinula (the nucleus as well as the greater part of this region lie outside of the pigment-cup and are not shown in the drawing).

Fig. 3 Diagram representing analogous structures in the retinulae of vertebrates and flatworms. A, retinula (rod) of frog (after Kepner and Foshee, '17, from Arey, '16); $B$, retinula of Prorynchus applanatus (after Kepner and Foshee, 17); $C$, retinula of Planaria maculata. Line 1 indicates the rhabdomes of the three retinulae; line 2 connects the ellipsoid of the frog with the analogous parts of the retinulae of Prorynchus and Planaria; line 3 , the myoid; $N$, nuelei. 


\section{ORIENTATION TO LIGHT IN NORMAL SPECIMENS}

With the exception of a few forms like Bdelloura, all of the species of triclads whose reactions to light have been studied are negative. The earlier investigators, Loeb ('93, '94), Hesse ('97), Parker and Barnett ('00), maintained that the species worked on do not orient to the direction of the rays of light to any marked degree, but simply tend to come to rest in the areas of least intensity. Later investigators, however, Walter ('07) and Mast ('10), found evidence of fairly precise orientation.

\section{Orientation to a horizontal beam of light}

Planaria maculata moves over the substratum with an even, gliding motion. During this process the anterior tip of the head as well as the cephalic lobes are considerably elevated above the rest of the body. There is no continual pronounced side-to-side movement of the anterior end. A given specimen may, however, at irregular intervals raise the anterior end and wave it from side to side, but this reaction usually continues only for a brief interval, after which the animal resumes its normal gliding course. This 'waving' reaction is what Walter ('07, p. 49) has termed 'wigwagging movements.' He considers 'wigwagging movements' as attempts "on the part of the worm to become adjusted to the stimuli acting upon it." Another movement of this general character which I have designated as the 'twisting reflex' will be taken up later.

A specimen which is illuminated by light from a single source moves fairly directly away from the source. If, after such a specimen has become oriented in a horizontal beam of light, it is illuminated laterally by a sudden change in the direction of the rays through $90^{\circ}$, it usually turns directly away from the source of light, without preliminary trial movements, as indicated in figures 4 and 5. By referring to figure 4 , which is a cameralucida drawing, it will be seen that, in this experiment, the direction of the rays was changed five times and that the planarian turned directly from the light each time without trial movements. Approximately ninety camera-lucida drawings representing the 
effect of changes in the direction of illumination and the reactions of planaria were made. All of these are essentially the same as the one reproduced in figure 4. Moreover, the process of orientation was observed on many other occasions and it was found

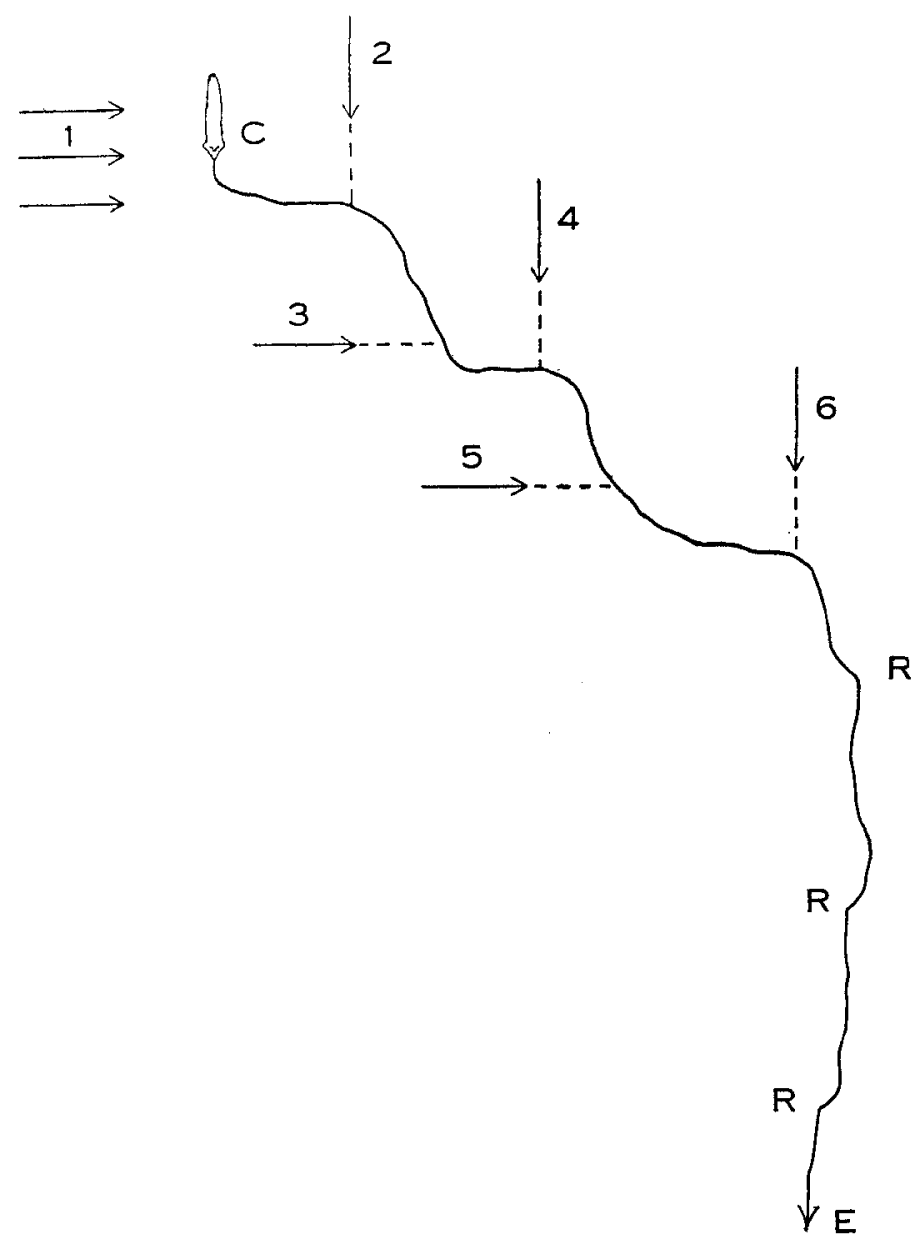

Fig. 4 Camera-lucida drawing of the path of a Planarian, showing the relation between changes in the direction of illumination and the direction of locomotion. $C-E$, path of specimen; $R$, point at which wandering reflex took place. Arrows 1 to 6 indicate successive directions of rays of light. Dotted lines extending from the arrows 2 to 6 indicate the position of the planarian on its path when the direction of the rays was changed. 
that the planaria practically always turned directly from the light without trial movements.

1. Extraneous reflexes during orientation. After a given specimen is oriented and is proceeding away from the source of illumination there are a number of different motor activities that can be noted. Two of these, although they do not seem to play any

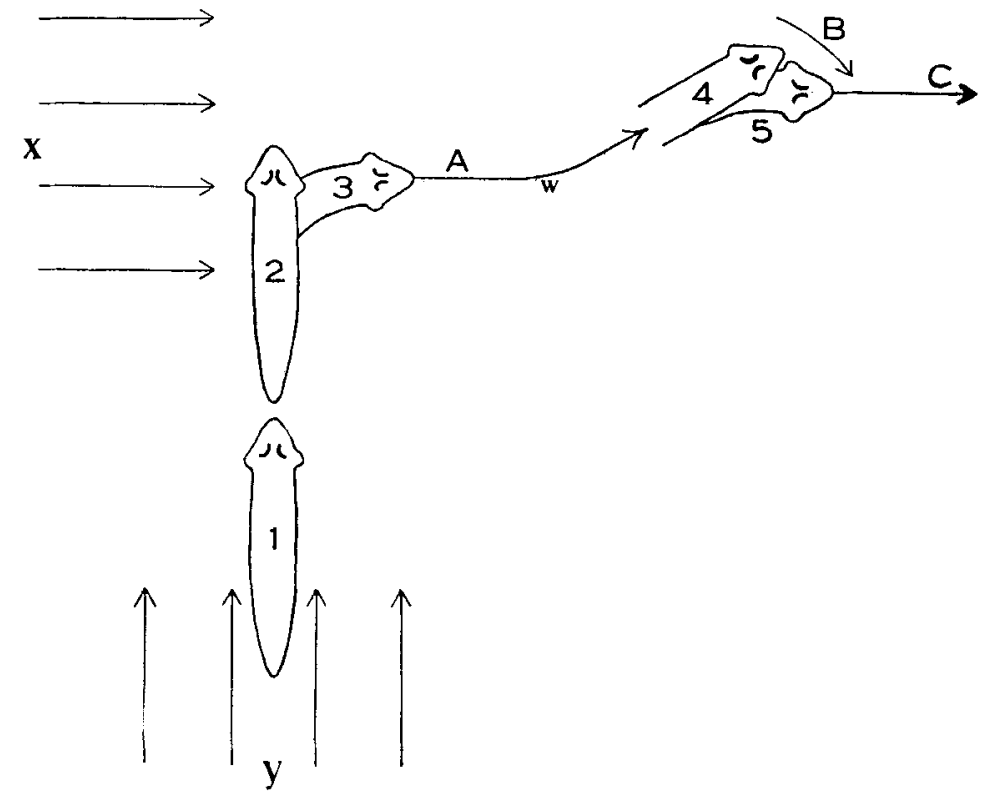

Fig. 5 Diagram representing orientation to light in normal specimens and 'wandering reflex.' The arrows $x$ and $y$ indicate the direction of the rays of light. $A, B$, and $C$, indicate path of specimen. $1,2,3,4$, and 5 , successive positions of specimen; $w$, point of beginning of 'wandering reflex.' When specimen reached position 2 the light $y$ was intercepted and light $x$ turned on.

significant part in the normal process of orientation, will be described here because they later become of great interest in other reactions to light. The first of these I have designated the 'wandering reflex.' After an animal is oriented, it takes a fairly straight course for a certain distance ( 1 to $4 \mathrm{~cm}$.), then it begins to wander toward the right or left. If the animal in this wandering turns far enough to allow the rays of light to enter the pig- 
ment-cup of the eye, it suddenly reorients and again proceeds directly from the source of stimulation as represented in figure $4, R$. In referring to this figure one might ask why this 'wandering reflex' with the subsequent reorientation occurred only after the direction of the rays was changed at 6 and not after the preceding changes. The answer to this lies in the fact that after the preceding changes in the direction of the rays the animal was not allowed to proceed far enough, for, as previously stated, the animal always proceeds a certain distance before the wandering commences. In practically all of the numerous records made of the orientation to light in Planaria maculata this wandering reaction and reorientation occurred one or more times.

The wandering of specimens from the path of orientation and the subsequent reorientation as soon as the animal turns enough to let the light rays enter the pigment-cup suggests strongly that once an animal is oriented it receives no orienting stimulation unless it leaves the path of orientation. This will be considered in detail in another section.

The second type of rèaction alluded to above has been designated the 'twisting reflex.' Whenever a planarian is proceeding from a source of light, it pauses at irregular intervals and twists the anterior end so that the ventral surface tends to be directed upward. Under strong illumination this response is exhibited at intervals of approximately 3 to $4 \mathrm{~cm}$.

It is interesting to note that decapitated specimens never give the twisting reflex. When the anterior ends of such specimens are allowed to regenerate, this reflex is not exhibited until after the anterior end is almost fully developed. From a study of the sections of such animals, considerable evidence was obtained indicating that it is necessary for the regeneration of the 'brain' to be practically complete before the twisting reflex occurs.

Neither the twisting reflex nor the wandering reflex apparently plays any significant part in the normal process of orientation, but, as we shall see later, both play a paramount rôle in the orientation of forms with one eye removed.

2. Character of turning in animals during orientation in different intensities of illumination. In the description of the orientation 
of normal animals to a horizontal beam of light, it was noted that animals usually turn directly away from the light without any preliminary trial movements. This is certainly true in the majority of cases. A study of orientation in different intensities of illumination, however, reveals, among other things, that a given specimen may even turn first toward the light and then away from it.

If the lateral illumination is of a very low intensity, the animal orients by describing a rather broad arc of a circle with barely any perceptible bending of the body. If the intensity is somewhat higher, the animal does not describe this arc, but turns its head directly away from the source of stimulation, making a rather sharp angle in the contour of its body just posterior to the cephalic lobes. As the light intensity is increased, the animal still bends its head away, but the angle, i.e., the point of bending, becomes situated more and more posteriorly until it reaches the region of the pharynx. When the animal bends its body in the region of the pharynx, as it does only under the influence of very intense light, a peculiar reaction takes place. The specimen raises the anterior half of the body and violently turns it, first toward the light, then in the opposite direction until it faces directly away from the light, after which the head is lowered and the animal proceeds as usual. The reaction of turning the head first toward the light and then away under the influence of strong stimulation will be taken up later.

In studying the relation between the character of turning during orientation and the intensity of the light, no attempt was made to measure accurately the illumination because of the great individual variation and the great variation in the same specimen at different times. Then, too, in working continuously with a given animal, it becomes more and more indifferent to stimulation by light. The following detailed description will illustrate the character of the results obtained in all of the the numerous observations made.

On September 7, 1916, a specimen tested two hours after collecting described a rather broad arc of a circle in orienting in an illumination of 52 meter-candles (fig. $6, A$ ). When the 
specimen was then illuminated laterally with stronger light, viz., 75 meter-candles, the animal bent its body in the region just posterior to the cephalic lobes, thus turning the anterior end sharply away from the light. The point of bending occurred somewhat farther back (fig. $6, B$ ) when the animal was subjected to a lateral illumination of 208 m.c. When the lateral illumi-

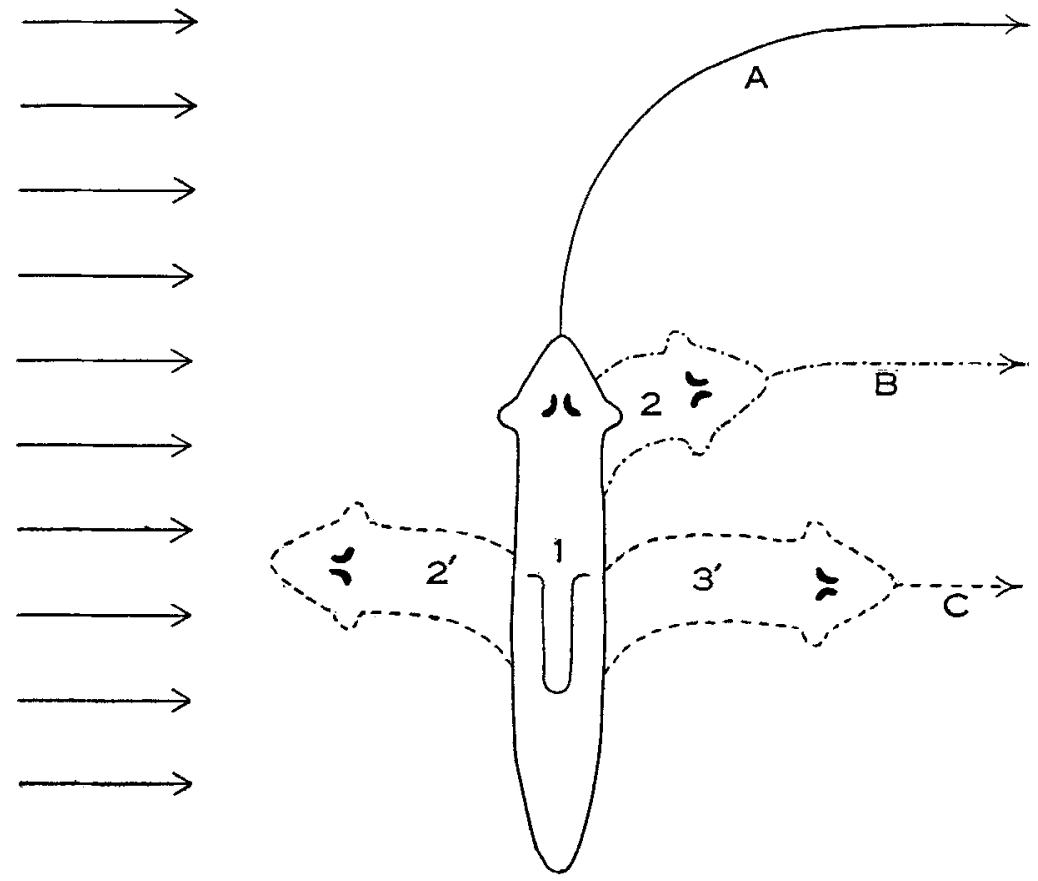

Fig. 6 Diagram representing orientation of planarians in different illuminations. Arrows indicate the direction of light. $A$, path of specimen in 52 metercandles; $B$, path of specimen in 208 m.c. ; 1,2 , successive positions of specimen; $C$, path in 3328 m.c., $1, \mathscr{2}^{\prime}, 3^{\prime}$, successive positions of specimen.

nation was increased to 3328 m.c., the bending occurred in the region of the pharynx, but first toward and then away from the light, and the reactions were very violent (fig. $6, C$ ).

These observations on the character of turning in specimens under the influence of increasing intensities of light are interesting when considered in relation to the nature of the nerve impulse from the eye to the musculature which causes the bending. When 
a planarian bends its body in a lateral direction, this can be conceived to take place either by a lengthening of the side toward the light or by a contraction of the side opposite the light, or possibly both. If the animal bends by lengthening one side, this is probably due to a contraction of the dorsoventral muscles of that side. This contraction would tend to flatten the body in a given region and hence elongate its contour. On the other hand, a contraction of one side would most likely be due to a contraction of the longitudinal muscles of that side. Pearl ('03) is of the opinion that in planaria while turning away from mechanical stimulation, this turning is due to a contraction of the dorsoventral muscles and, in consequence, to an elongation of the side away from the bending. In numerous experiments along this line, the author has been unable to satisfy himself as to which is true in orientation to light. The nerve fibers leading from the eye of a planarian must be connected indirectly with a rather complex system of muscles along either or both sides of. the animal. In an animal under comparatively weak stimulation, the nerve impulse most likely is transmitted to a rather localized region of the musculature, viz., to a region near the cephalic lobes. The fact that the point of bending gradually moves posteriorly as the stimulation increases strongly suggests that in such cases there is a greater and greater spread of the nerve impulse along the musculature of a given side as each successive increase in the stimulation takes place. This assumption of course, would not explain the reaction of bending first toward and then away from the light under the influence of very intense illumination. It is likely that the latter involves a different neuromotor mechanism, possibly analogous to protopathic stimulation in the vertebrate eye. In the human eye, for example, an intense illumination often involves a protopathic sensation entirely aside from the usual sensation of light. In this case the protopathic sensation involves a different mechanism than the usual sensation of light; it may, in fact, be invoked in a totally blind person (Sherrington, '98, page 967).

The reaction of bending the anterior end first toward and then away from the light is very similar to that described by 
Pearl ('03, p. 580) as a result of continued strong mechanical stimulation. He believes that "It indicates the effect of the organism as a whole on its reflexes." Boring ('12) has observed similar reactions in Planaria torva after continued directive illumination. He (p. 241) believes that-

It is quite conceivable that the abrupt reversal of directions for brief periods, the 'wild jumps,' are forms of a compensatory movement, which acts as a relief, not for the continued stimulation, but for the continued movement away from the stimulus. ... . . It is quite possible that these muscles (i.e., the ones which steer the animal to one side) after the continued contraction involved in prolonged movement to one side, become cramped, and there follows what is probably a natural physiological coördination, when the muscles on the other side contract suddenly and strongly, stretching the fatigued muscles.

Both of the investigators quoted above observed the bending of the animal first toward and then away from the stimulated side only after long-continued stimulation. While this reaction certainly does follow long-continued stimulation, I am not certain, judging from the results of numerous observations, that it is necessarily preceded by continued stimulation. When an animal is very strongly illuminated this reaction will follow immediately even though the animal has been previously subjected to very little photic stimulation. Such reactions unquestionably occur in earthworms and fly larvae immediately after stimulation. It is hoped that this matter can be taken up later in more detail. It would raise some interesting questions if short strong stimulation produced the same effect as long-continued weak stimulation.

\section{FUNCTION OF THE EYES}

\section{A. Reactions to light in specimens with both eyes removed}

The majority of investigators who have worked on the question of the function of the eyes in planarians have reached the conclusion that these organs play very little part in the character of the responses to light. Thus, as previously stated, Loeb ('94), Hesse ('97), and Parker and Burnett ('00) maintain that decapitated planarians react essentially the same as normal specimens, but that all reactions require considerably more time. 
In experiments on decapitated and normal Planaria torva, Parker and Burnett concluded (p. 385):

Planarians without eyes react to the directive influence of light in much the same way as those with eyes, in that they have a tendency to turn away from the course when directed toward the source of light and to keep in it when directed away from the source, though with less precision and often to less extent than planarians with eyes.

Planarians with eyes move more rapidly $(1.12 \mathrm{~mm}$. to $1.04 \mathrm{~mm}$. per sec.) than those without eyes (0.89 to $0.82 \mathrm{~mm}$. per sec.) and those moving away from the light $(1.12 \mathrm{~mm}$. and $0.89 \mathrm{~mm}$. per sec.) than those moving toward it $(1.04 \mathrm{~mm}$. and $0.82 \mathrm{~mm}$. per sec.)

Opposed to these results we find that Lillie ('01) maintains that posterior headless pieces of Dendrocoelum lacteum do not exhibit the usual responses to light. Also, Mast ('10) maintains that an undetermined marine turbellarian with the eyes removed fails to orient to a horizontal beam of light, while normal specimens orient fairly precisely.

The present experiments on the reactions of specimens with both eyes removed were designed to answer two questions: 1 . Does removal of the eyes affect the character of the responses to light? 2. Does removal of the eyes affect the rate of locomotion?

The animals used in these experiments were anesthetized and their eyes cut out in the manner described in the section on methods. After each animal was operated on, it was allowed approximately twenty-four hours to recuperate. If, after this time, the animal showed any distortion about the head it was discarded. Then, as a further check, each animal was, after the experiment, fixed, sectioned, and stained. These sections were carefully examined, and the records of any animal were discarded if the sections contained any trace of the eye which was removed or if there was any deep cut into the 'brain.'

By using this technique it is surprising how neatly a small organ like the eye can be removed. In successful operations, the only noticeable difference from normal specimens besides the absence of the eyes is a slight dislocation of the pigment of the body surface in this region (fig. 7). In some cases even this cannot be detected. The sections, in the majority of cases, revealed the fact that the 'brain' had not been cut at all in the 
removal of the eyes. Throughout this series of experiments it was found essential never to use specimens which showed any distortion of the head. Such distortions are often followed by abnormal motor activities.

1. Character of reactions to light. Specimens with both eyes removed move about essentially like normal specimens. They exhibit the twisting reflex (p. 75) and occasional 'wigwagging movements' (p. 72) just as do normal specimens. When observed in non-directive light, no difference can be observed between them and normal specimens in either the rate or nature

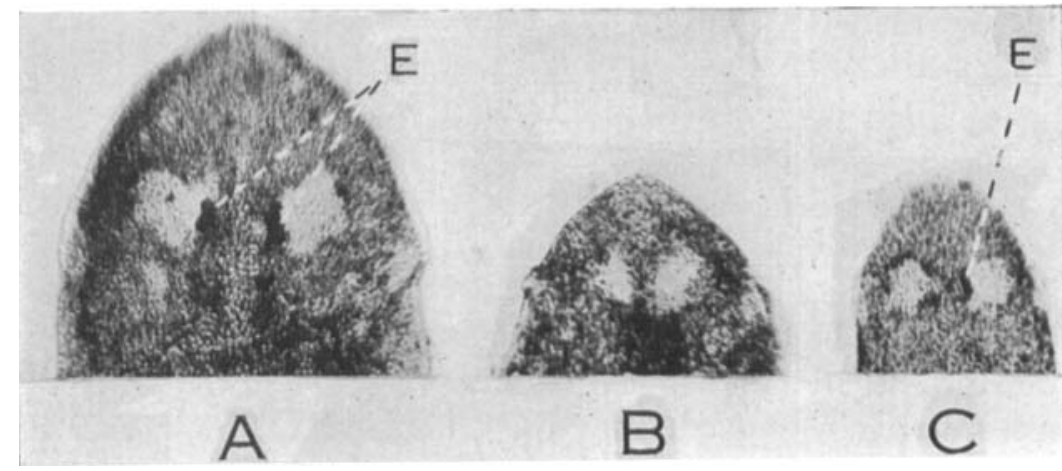

Fig. 7 Photographs from unretouched negatives of normal and operated specimens. All magnified 30 diameters. $A$, normal specimen; $E$, eyes; $B$, specimen with both eyes removed; $C$, specimen with left eye removed; $E$, eye. Note the lack of distortion in those specimens which have been operated on.

of locomotion. This is in marked contrast to the behavior in decapitated worms.

Although no difference can be detected between the reactions of normal specimens and specimens with both eyes removed when in non-directive light, this is not the case when observed in directive light. Specimens with both eyes removed do not orient to a horizontal beam of light as do normal specimens. This is well illustrated in the following detailed description of one of the twenty experiments made, the results of which are essentially the same. 
The specimen used in this experiment was first tested in a horizontal beam of light in which it was found to orient very precisely. The animal was then anesthetized with $\mathrm{CO}_{2}$ and both eyes removed. Twenty-four hours after the operation, the animal was again tested and its movements traced with a camera lucida. This tracing is reproduced in figure 8. At the beginning of the experiment, the animal was laterally illuminated and it proceeded for a short distance at right angles to the rays of light and then turned directly toward the light. Movement in this direction continued for only a short distance, when it turned again and proceeded in a diagonal path away from the light. This path soon led out of the beam of light into the shadow. Twice as the animal attempted to proceed from the shadow back into the light it hesitated, and after a sort of 'avoiding reaction' proceeded back into the shadow (fig. 8, 1 and 2). The third time it came to the margin between the light and the shadow it passed into the light without any perceptible reaction. The direction of the light was now changed through an angle of $90^{\circ}$ (fig. $8, P$ ). The animal described a very irregular course away from the second light source. While proceeding away from this source it again moved from the illuminated region into the shadow and vice versa on two separate occasions, with no apparent reaction (fig. 8, 3 and 4.). After these observations were made, the animal was fixed, sectioned, and stained. A study of these sections revealed that the eyes had been entirely removed and that there was no apparent injury to the 'brain' or other organs.

If, now, the reactions of this specimen in a horizontal beam of light are compared with those of normal specimens in similar illumination, it becomes evident that orientation is dependent upon the eyes. This conclusion is, moreover, strongly supported by the fact that blind specimens again orient precisely after the eyes regenerate.

Although the eyes are clearly functional in orientation, the evidence at hand indicates that there is in eyeless specimens at times some indication of a slight orientation to the rays of light. The question then arises as to what factors are involved in the slight tendency toward orientation in these specimens. The an- 
swer to this, I think, lies in the fact that, while the post erior end of the animal is sensitive to light, the anterior end, exclusive of the eyes, is more so.

In regard to the anterior end, regardless of the eyes, being more sensitive to light than the posterior, Walter ('07, p.123) says:

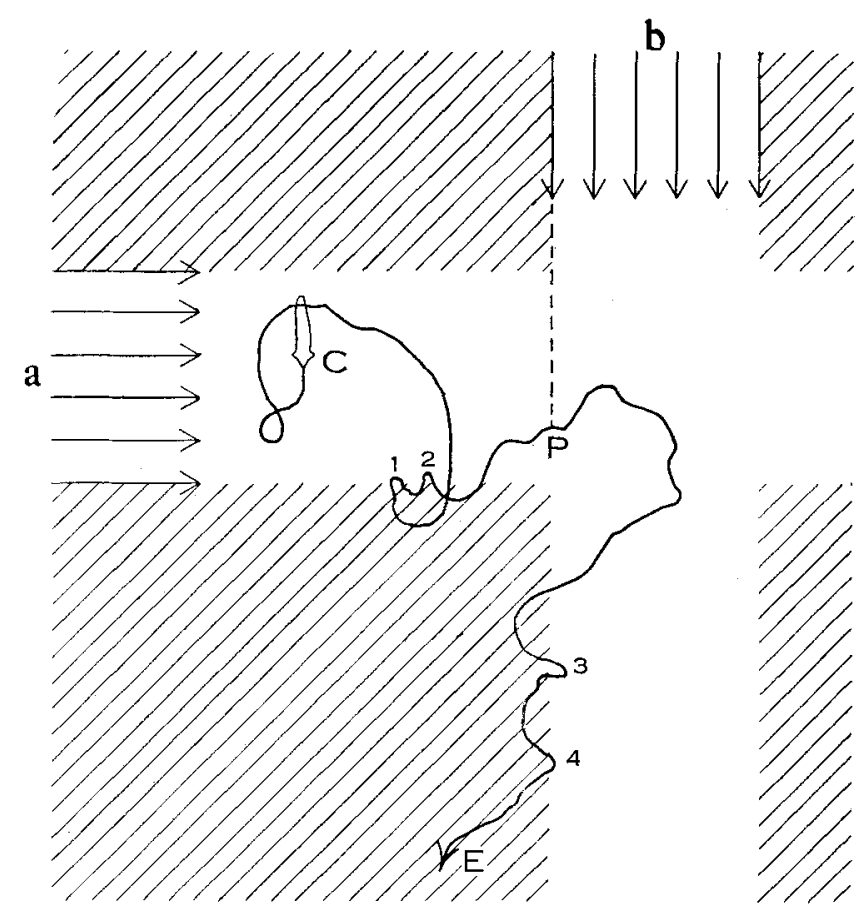

Fig. 8 Camera-lucida tracing of the path in a horizontal beam of light of a specimen with both eyes removed. Arrows $a$ and $b$ indicate the direction of the rays of light. $C-E$, path of animal. When the animal reached the point $P$, light $a$ was turned off and light $b$ was turned on. At points 1 and 2 the animal gave a kind of 'avoiding reaction.' This did not occur at 3 and 4 .

Again, when a small beam of sunlight passing through a pinhole in an opaque screen was directed locally to different parts of a gliding Planaria maculata, it was found that tropic response would occur in case one side of the anterior end was illuminated, and that it was not necessary for the eye itself to be included in the illuminated area to obtain such responses. However, when the middle of the body or the posterior end was similarly stimulated the worm could not be made to turn. 
As it is very improbable that the anterior end of a planarian can be illuminated without allowing a certain amount of light to enter the eyes, Walter's experiments were repeated, using, however, specimens the eyes of which had been carefully cut out, and a horizontal beam of light instead of the localized point as in the above experiments. It was found that if a beam of light was thrown laterally on the anterior end of such a worm, it turned away from the source of light in the majority of cases. It is important to notice, however, that this turning was not nearly so definite or precise as in the case of animals with eyes. A given specimen very often turned toward the light, swerving all the way around and thus proceeded away from the source of stimulation. The turning of such eyeless specimens was much more indefinite if the entire animal was illuminated instead of the anterior end.

As the anterior end is more sensitive to light than the posterior, the animal would most likely maintain a position in regard to the light source such that the posterior end would shade the more sensitive anterior end. Such a position would tend to keep the animal directed away from the light and would explain the slight tendency to orientation observed in such specimens. It must not be supposed, however, that all of the reactions of specimens without eyes can be ascribed to this differential sensitivity of the anterior and posterior regions because a decapitated worm still proceeds, in general, away from the light. Although this is true, a decapitated worm does not show the slight tendency toward orientation such as is found in animals with both eyes removed.

2. Rate of locomotion. As pointed out above, no difference in the rate of locomotion can be observed under ordinary conditions between normal specimens and those which have had both eyes removed. In order to test this accurately, however, the following experiments were devised, using both directive and non-directive illumination. The non-directive illumination was furnished by placing a 125-watt gas-filled lamp 30 c.m. above a circular aquarium in which the animals were moving. The directive light was furnished by the same apparatus used to test 
the reactions of specimens in a horizontal beam of light. In both cases the rate of locomotion was determined by means of a pantograph previously described in the section on methods.

Ten normal specimens were placed in a dark room for twentyfour hours and then their rate of locomotion both in directive and non-directive illumination was ascertained. Throughout the experiment the animals were kept in the dark when not being observed, so as to keep the preliminary light environment as nearly constant as possible. After the rate of locomotion for the ten normal specimens had been ascertained, both eyes were

The effect on the rate of locomotion of removing only the eyes as compared with the effect of removing the entire anterior end

\begin{tabular}{|c|c|c|c|}
\hline & \multicolumn{2}{|c|}{$\begin{array}{l}\text { AVERAGE RATE OF } \\
\text { LOCOMOTION IN } \\
\text { MTLLIMETERS } \\
\text { PER BECOND }\end{array}$} & \multirow{2}{*}{$\begin{array}{c}\text { NUMBER } \\
\text { OF } \\
\text { TRIALS }\end{array}$} \\
\hline & $\begin{array}{c}\text { Directive } \\
\text { light }\end{array}$ & $\mid \begin{array}{c}\text { Non- } \\
\text { direotive } \\
\text { light }\end{array}$ & \\
\hline Ten normal specimens.......... & 1.18 & 1.11 & 40 \\
\hline \multirow{3}{*}{$\begin{array}{l}\text { The same with both eyes removed: } \\
\text { 1) Two hours after removal of eyes........................ } \\
\text { 2) Twenty-four hours after removal of eyes...... }\end{array}$} & & & \\
\hline & & 1.25 & 39 \\
\hline & 1.10 & 1.08 & 55 \\
\hline The same with anterior end removed: & & & \\
\hline Twenty-four hours after operation.. & 0.62 & 0.71 & 45 \\
\hline
\end{tabular}

removed from each specimen and, after twenty-four hours, their rates of locomotion were again measured. In the case of nondirective illumination, the rate of locomotion was also obtained two hours after the removal of the eyes. Then, in order to see if the removal of the anterior end had the same effect as removing only the eyes, thesame specimens were decapitated, and after twenty-four hours their rates of locomotion were again ascertained.

The results of these experiments are tabulated in table 1 . This table shows that, in directive illumination, the average rate of locomotion for the ten normal specimens was $1.18 \mathrm{~mm}$. per second; that after the eyes were removed, the rate in the same 
specimens in the same illumination was $1.10 \mathrm{~mm}$. per second; and that, after the removal of the anterior end, the rate was only $0.62 \mathrm{~mm}$. per second. The table also shows that essentially the same results were obtained in the case of non-directive illumination. It shows, moreover, that in specimens tested two hours after the removal of the eyes the rate of locomotion actually increased. This is, no doubt, due to the mechanical stimulation of removing the eyes which has not yet had time to wear off, for, in normal specimens, shortly after small incisions are made in the dorsal surface, the rate of locomotion is similarly increased.

These results show that the rate of locomotion is not appreciably affected by the removal of the eyes, whereas it is greatly affected by the removal of the anterior end, and they indicate very clearly that the photoreceptors which receive the orienting stimulus are not the ones which control the rate of locomotion. It has been shown by Walter ('07, p. 57) that, in general, planarians move faster in higher intensities than in lower. The photoreceptors involved in this increase of the rate of locomotion under increased intensity of illumination as well as in the experiments just described are other than the eyes-very probably the general body surface.

3. Discussion of experiments in relation to former investigations. The results of the preceding experiments are in accord with those of Lillie ('01) and Mast ('10) in regard to the character of the response to light, but are at variance with the results of Loeb ('94), Hesse ('97), and Parker and Burnett ('00) both in regard to the nature of the responses and the rate of locomotion. The question immediately arises as to what causes the disparity between these results and those of the latter investigators.

In regard to the nature of the response in specimens with both eyes removed, the answer probably can be found in the fact that the species used by the former investigators did not normally orient with any great degree of precision to the directive influence of light. There is no doubt that many planarians do not orient to light, and, of course, one would not expect to find any great change brought about by the removal of the eyes, if the eyes did not function in the normal animal. 
In regard to the rate of locomotion in specimens with both eyes removed, the disparity between the results of this paper and those of the former investigators undoubtedly lies in the fact that they drew conclusions regarding the effect of removing the eyes from the behavior of decapitated specimens. From the results given in this paper, it is evident that such conclusions are not valid, because removal of the anterior end itself, regardless of the eyes, has a profound effect on the rate of locomotion. If the entire ventral surface of a planarian is functional as an organ of locomotion, a very simple explanation of the decrease of the rate in decapitated worms suggests itself. Removal of the anterior end would remove a part of the organ of locomotion and hence would undoubtedly decrease the rate of movement. It is very improbable, however, that this can explain such a great decrease. The general effect of the operation and possibly the loss of the 'brain' act upon the general physiological tone of the animal, causing locomotion, among other physiological activities, to be retarded.

\section{B. Reactions to light in specimens with one eye removed}

In regard to the reactions of planarians with one eye removed, Mast ('10, p. 132), in a paper already referred to, makes the following statement:

Planaria with one eye removed, either by gouging it out or by cutting off one side of the anterior end obliquely, turn continuously from the wounded side for some time, evidently owing to the stimulation of the wound, since after this is healed they tend to turn in the opposite direction. After regeneration is nearly complete they orient practically as accurately as normal specimens.

Unfortunately, from the standpoint of the present investigation, no note was made of just how far the eye itself was allowed to regenerate in such specimens before accurate orientation to light was observed.

The present experiments were designed to ascertain how accurately specimens with one eye orient to the directive stimulation of light and to find out, if possible, the mechanism of this orientation. 
In these experiments, exactly the same technique was employed and the same precautions were observed as in the experiments of the preceding sections. The animals were anesthetized with $\mathrm{CO}_{2}$ and one eye removed with a fine knife, as has been described (fig. 7). After the removal of an eye, the animals were given eight to twenty-four hours to recover from the operation. At this point any specimen which showed any distortion of the head or any loss of the bilateral symmetry of the contour of the anterior end was discarded. It is to be noted that in removing one eye there is more tendency to disturb the bilaterally symmetrical contour of the anterior end than in the case where both eyes are removed. Any disturbance of the contour of the head is often followed by abnormal locomotor disturbances. After each experiment, the animals were fixed, sectioned, and stained as in the preceding section. Again, the records of all animals in which there was any injury to the 'brain' or incomplete removal of the eye were discarded.

When observed in non-directive light, specimens with one eye removed travel about, apparently, in every respect like normal individuals. In neither directive nor non-directive light is there any evidence of sluggishness, circus movements, or other abnormal motor activities. The absence of circus movements is in marked contrast to the results of Mast ('10, p. 132).

In studying the process of orientation in specimens with one eye removed, the paths of twenty-nine individuals were traced by means of a camera lucida. All of these tracings are essentially like the one reproduced in figure 9 . This tracing was made from observations on a specimen twenty-four hours after the right eye had been removed. Just prior to the removal of the eye the specimen oriented accurately when illuminated laterally on either side. The tracing shows that after the removal of the eye the animal oriented immediately and precisely like normal specimens whenever the direction of the rays of light was changed so as to illuminate the normal side (fig. $9, N$ ); but when the 'blind' side was illuminated, it did not react immediately nor did it orient like normal specimens. In two cases when the 'blind' side was illuminated, viz., after light 1 and 3 were turned 
on (fig. 9, 1 and $3, W^{\prime}$ ), the animal proceeded for a certain distance at right angles to the rays of light until a wandering reflex caused the animal to turn far enough toward the light to allow the rays of light to enter the remaining eye. After this occurred the animal oriented accurately by describing a small circular path away from the light. In another case when the 'blind'

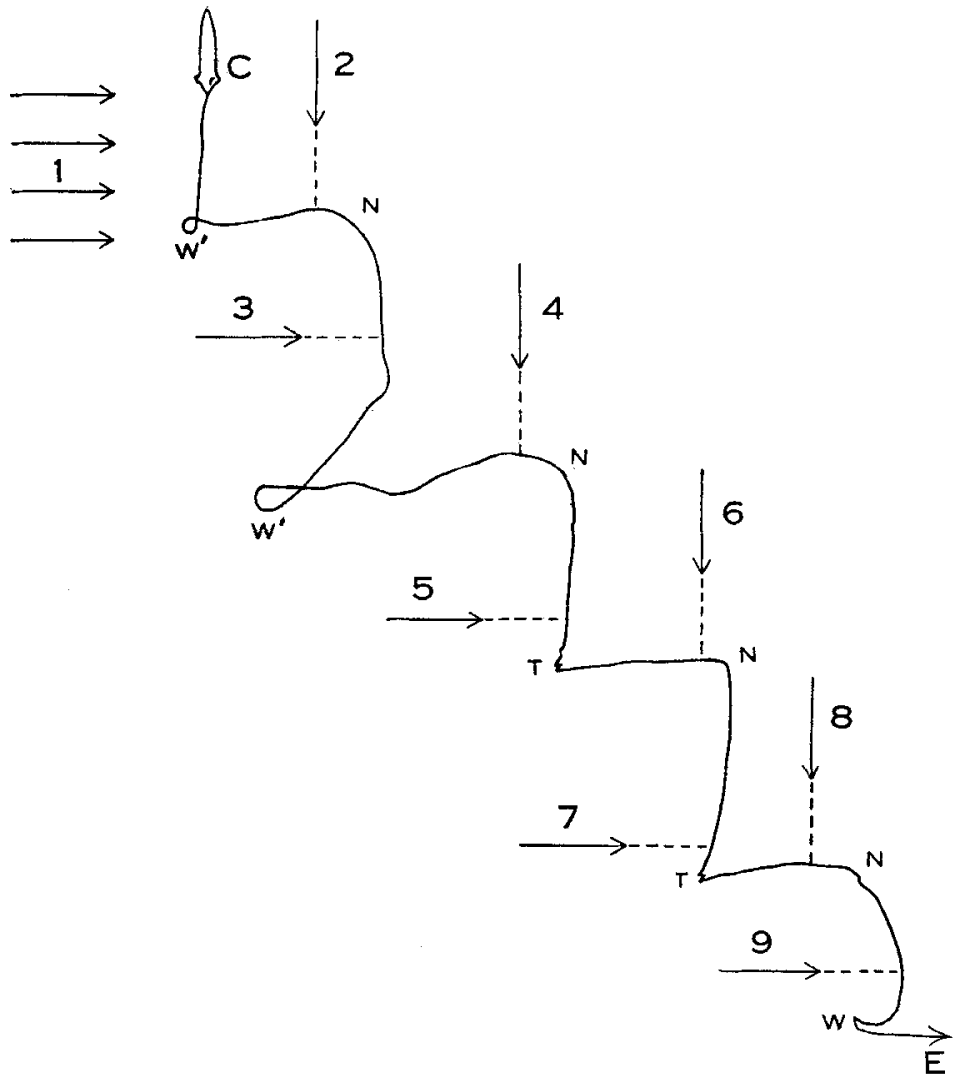

Fig. 9 Camera-lucida drawing of path of specimen with the right eye removed in a horizontal beam of light. Arrows 1 to 9 indicate successive directions of the rays of light. $C-E$, path of specimen; $N$, direct orientation following illumination of the left, i.e., normal side; $T$, orientation by means of the twisting reflex following illumination of the right, i.e., 'blind' side; $w$, orientation by means of the wandering reflex following illumination of the 'blind' side; $w$ ', orientation by means of 'wandering reflex' modified by a greater rapidity in the movement of the animal. 
side was illuminated, viz., after light 9 was turned on, the animal, in consequence of a wandering reflex, turned toward the light; but, in this case, instead of describing a circular path away from the light, the animal oriented by turning toward the side containing the eye (fig. 9,9 and $W$ ). The rate of movement seem to determine which of these two reactions follows when such specimens orient by means of the wandering reflex. This will be taken up later in greater detail. In the two remaining cases in which the animal was illuminated on the 'blind' side, viz., after lights 5 and 7 were turned on, the animal proceeded at right angles to the light until it gave the twisting reflex (fig. 9, 5 and $7, T)$. During this reaction the anterior end was twisted and directed toward the light in such a manner that the light entered the remaining eye. In consequence of this, the animal oriented accurately by turning directly away from the light.

The above observations clearly indicate that when a specimen is illuminated on the 'blind' side, it does not orient until it moves in such a manner as to allow the light to enter the remaining eye. When this occurs the specimen orients quickly and accurately. The mechanism of orientation in such a specimen can best be explained by means of diagrams (fig. 10). If, as the animal is illuminated on the 'blind' side and is proceeding at right angles to the rays of light (fig. 10, $A, 1$ ), it gives a wandering reflex toward the 'blind' side (fig. 10, $A, 2$ ) to such an extent that the rays of light enter the posterior region of the pigment-cup, the animal turns sharply (fig. 10, $A, 3$ and 4) toward the normal side instead of away from it as it ordinarily does. In rapidly moving specimens this reaction is often modified. If the animal is moving rapidly, it is often carried around so far that the light strikes the rhabdomes of the center of the fundus of the pigmentcup apparently before it has had time to react to the illumination of the rhabdomes of the posterior edge of the cup. If this happens, the animal turns away from the stimulated side instead of toward it as in the former case. In other words, it continues to turn toward the 'blind' side until it is oriented. This reaction results in a small circle in the path (fig. 10, $A, 2,3^{\prime}-5^{\prime}$ ). A third method of orienting to the rays of light, when the animal 


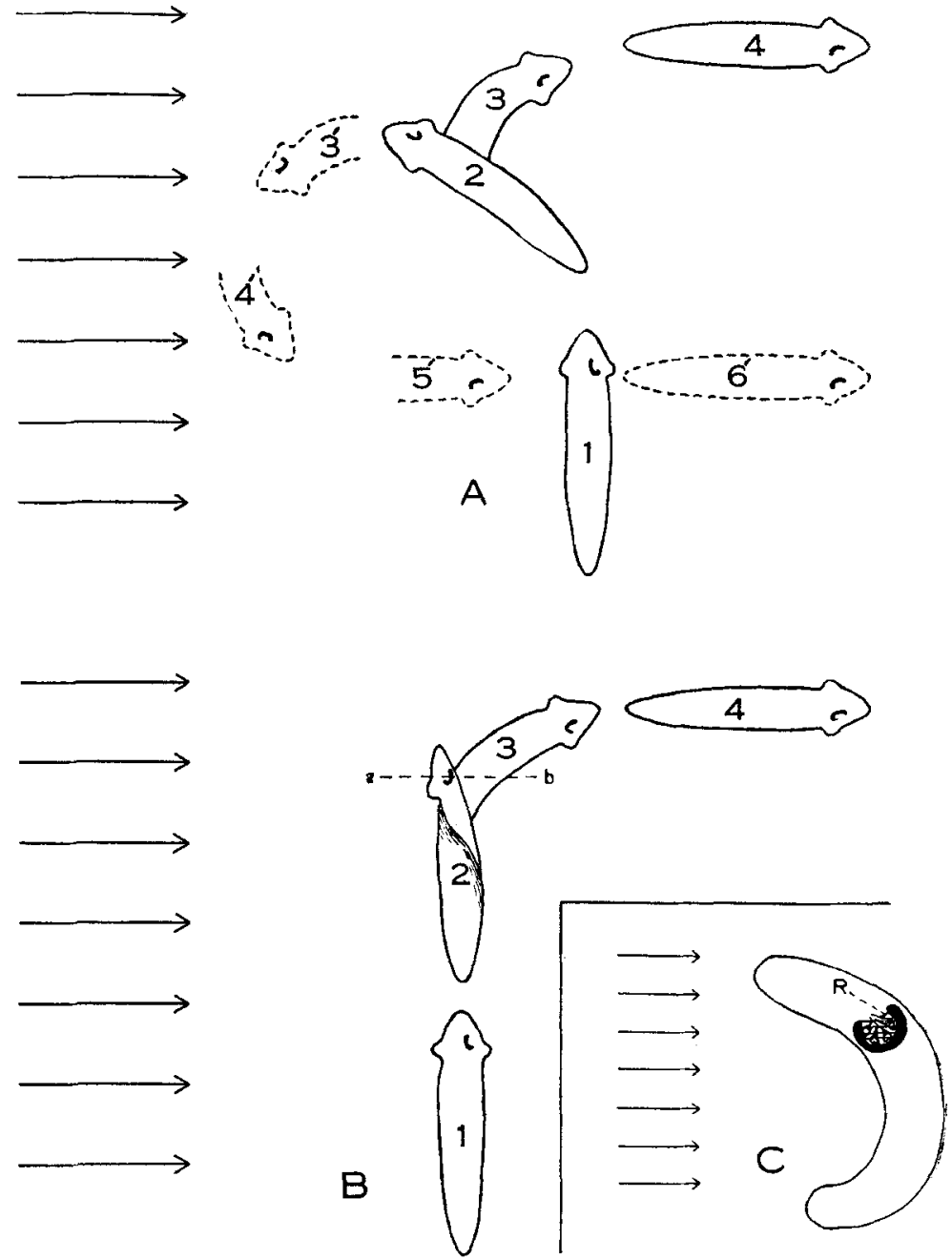

Fig. 10 Diagrams illustrating process of orientation in specimens with left eye removed, when illuminated laterally from the left, i.e., the 'blind' side. The arrows indicate the direction of the rays of light. $A$, orientation by means of 'wandering reflex;' $1,2,3$, and 4 , successive positions of animal; $1,2,3^{\prime}, 4^{\prime}, 5^{\prime}$, and $6^{\prime}$, successive positions of the animal if it is moving rapidly; $B$, orientation by means of 'twisting reflex;' 1 to 4 , successive positions of specimen. Insert $C$ represents a diagrammatic cross-section of specimen in $B$ through the plane $a-b ; \mathbf{R}$, position of rhabdomes which are illuminated in such reactions. 
is illuminated from the 'blind' side, is by means of the twisting reflex. When an animal, moving at right angles to the direction of the rays of light, gives the twisting reflex it very often bends the side containing the remaining eye so far toward the light that the rhabdomes lying along the ventral surface of the pigment-cup are stimulated. (fig. 10, $B$ and insert $C$ ). If this takes place, the animal sharply orients by turning toward the stimulated or normal side (fig. 10, $B, 1-4$ ).

The results presented above show that specimens with one eye orient normally when the side containing the eye is illuminated; but that when the 'blind' side is illuminated, there is no true orientation unless the animal moves in such a manner as to allow the rays of light to illuminate some of the rhabdomes of the eye of the normal side.

The most interesting feature in regard to the process of orientation in such specimens is that when they are illuminated on the 'blind' side they very often turn toward the side containing the eye. Since turning is due to stimulation of the eye, such specimens turn toward the eye which is stimulated instead of from it as ordinarily occurs in normal orientation. In them, also, stimulation seems limited to certain portions of the eye and this seems to indicate that the direction of turning depends upon the localization of the stimulus within the eye. From a structural standpoint it indicates that the rhabdomes of each eye are arranged in two (or more) definitely localized sensory regions-the stimulation of one region resulting in the animal's turning away from the side containing the eye and the stimulation of the other resulting in a turning in the opposite direction. If there are such regions in the eye can these regions be accurately outlined? This problem will be taken up in the next section.

As has been pointed out above, Mast ('10, p. 132) found that Planaria with one eye removed by gouging it out or by cutting off the anterior end obliquely move continuously from the wounded side, and that, later during the process of regeneration, they have a tendency, when stimulated by light, to move toward the side containing the newly regenerated tissue. In our experiments we did not obtain reactions of this sort. Mast maintains 
that the first tendency to move away from the wounded side is probably due to the stimulation of the wound. The absence of any movements of this nature in specimens used in the present work is most likely due to the fact that no great amount of damage was done to the surrounding tissues in removing the eye. Later, during the process of regeneration, the tendency of the animals in Mast's experiments to move away from the side containing the newly regenerated tissue showed, according to him, that this newly formed tissue was more sensitive to light than the old. The absence of this tendency in the present experiments may again be due to the small amount of injury to the animal during the removal of the eye, and consequently, the lack of any large amount of regenerating tissue.

\section{Localized sensory regions in the eye}

1. Extent of localized sensory regions. The experiments of the preceding section demonstrate that two opposite reactions may follow from the illumination of different regions of the same eye. The experiments in this section were designed to outline as accurately as possible these regions of the eye.

It will be remembered that the eye of Planaria maculata consists of a number of sensory rhabdomes enclosed by an opaque pigment-cup: Because of this opaque pigment-cup, the entire eye may be illuminated and yet only a portion of the rhabdomes will receive this illumination. The area containing the illuminated rhabdomes in any case can be fairly precisely ascertained, provided the structure of the eye is known and parallel rays of light are used.

The apparatus used in these experiments was constructed as follows: A 125-watt gas-filled lamp was blackened except for a small circular area $5 \mathrm{~mm}$. in diameter. A tube about $5 \mathrm{c.m}$. in diameter and $45 \mathrm{~cm}$. in length was attached to the lamp over the circular area. At equal intervals along the length of the tube, three diaphragms containing circular openings $5 \mathrm{~mm}$. in diam. were placed. The beam of light thus produced consisted largely of parallel rays and was large enough to cover an entire eye. The tube with the lamp attached could be shifted to throw a beam of light in any direction desired. 

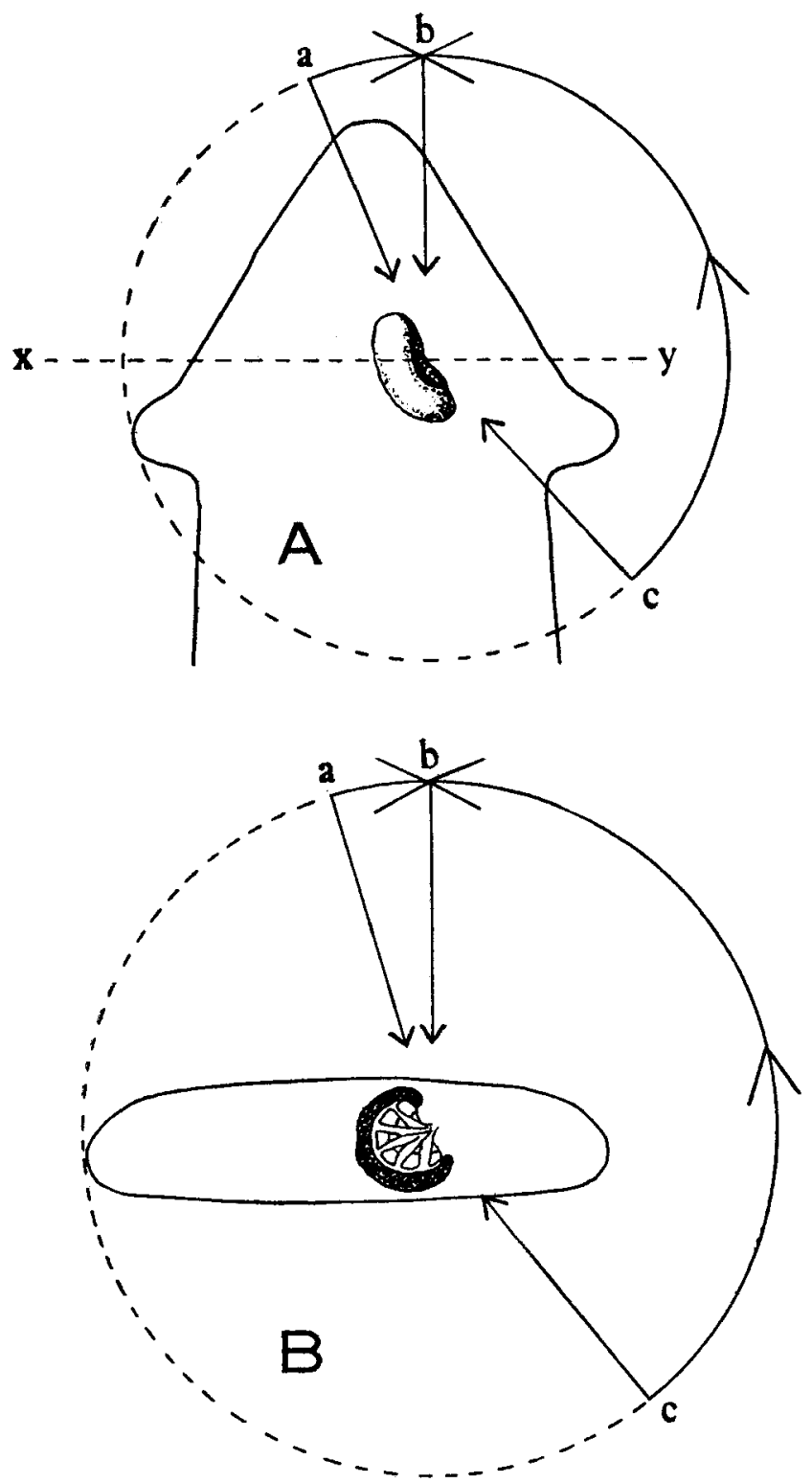

Fig. 11 Diagram representing the direction of the turning when a specimen with left eye removed is illuminated from different directions. $A$, dorsal view of specimen illuminated from different points in the frontal plane; $B$, specimen il- 
In order not to confuse the reactions resulting from the illumination of one eye with those following from the illumination of two eyes, all animals used in these experiments had one eye removed. The same specimens were used as in the preceding section.

Let us consider first the reaction of a specimen with the left eye removed when the eye is illuminated from different angles in the horizontal plane of the animal.

If the beam of light comes from a point directly in front of the animal, it turns the anterior end to the right, i.e., toward the normal or stimulated side (fig. 11, $A, b$ ). The same reaction follows if the source of light is shifted slightly to the left of the median line (fig. 11, A, a). As, soon however, as the light is shifted far enough to the left of the median line as to place the pigment-cup between the source of illumination and the sensory rhabdomes, no reaction follows (fig. 11, $a-b$ ). When the rays of light illuminate the eye from any point to the right of the median line, the animal turns in an opposite direction, i.e., it turns away from the normal or stimulated side (fig. 11, b-c). Here, just as with the previous case, as soon as the source of illumination is carried far enough to place the pigment-cup between it and the rhabdomes no reactions follow.

The same type of response is obtained when the specimen is illuminated from various points in the transverse vertical plane of the eye. If the rays of light illuminate the animal from a point directly above the eye, the specimen reacts by turning toward the normal or stimulated side (fig. $11, B, b$ ) If the source of illumination is shifted to the left of the vertical line the animal responds in the same manner (fig. 11, $a-b$ ). If, however, the rays of light illuminate the animal from any point to the right of the vertical line, the specimen responds by turning away from the normal or stimulated side (fig. 11, $B, b-c$ ). As in the previous

Iuminated from different points in the transverse, vertical plane of the eye. Section taken along $x-y$ of $A$. If the light enters the eye from any point between the arrows $a-b$, the specimen turns toward the normal side. If the light enters the eye from any point between the arrows $b-c$, the specimen turns away from the normal side. No reaction follows if the eye is illuminated from any point along the broken line $a-c$. 
case, whenever the light is so placed that the pigment-cup shades all of the rhabdomes, no reaction follows (fig. 11, $B, a-c$ ).

Let us now consider precisely which rhabdomes are illuminated under the various conditions mentioned above. It will be remembered that when Planaria is illuminated from directly in front, or directly above, or to the left of these points, it turns away from the side containing the eye, i.e., to the left. Now,
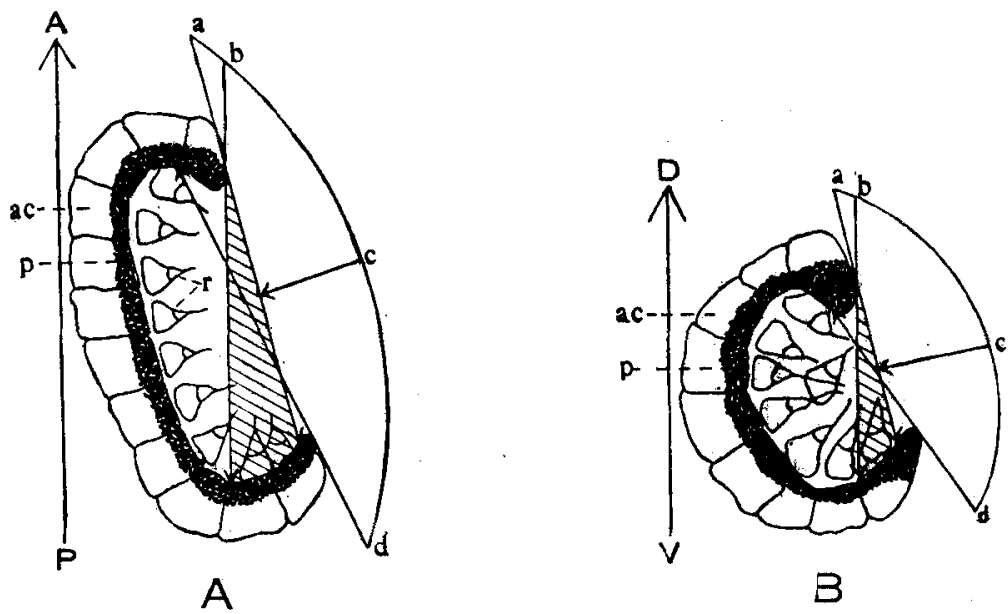

Fig. 12 Diagrams made from camera-lucida drawings representing the rhabdomes which are illuminated when light enters the eye from various directions. $A$, eye seen in frontal section; $B$, eye seen in transverse section; $A-P$, longitudinal axis of animal; $D-V$ dorsoventral line; $a c$, accessory cells forming pigment-cup; $p$, pigment-cup; $r$, rhabdomes. Light entering the eye from any point between $a-b$ illuminates only the rhabdomes in the area which is cross-hatched. Light entering the eye from any point between $c-d$ illuminates only certain rhabdomes of the unshaded regions. Light from any point between $b-c$ may illuminate rhabdomes of both the shaded and unshaded regions.

when light enters the right eye from a point directly in front of the eye, or slightly to the left of this point, the only rhabdomes which are illuminated are those lying along the outer, posterior edge (fig. 12, $A, a-b$ ). The remaining rhabdomes are shaded by the anterior edge of the pigment-cup. In the same manner, when light enters the eye from a point directly above the eye, or slightly to the left of this point, the only rhabdomes illuminated are those placed along the outer ventral edge of the pigment- 
cup (fig. 12, $B, a-b$ ). The remaining rhabdomes, in this case, are shaded by the dorsal edge of the pigment-cup. We may consequently conclude that illumination of the rhabdomes lying along the outer posterior edge and the outer ventral edge of the eye-cup is followed by turning toward the side bearing the eye. Which rhabdomes, then, are illuminated when the animal turns away from the side containing the eye?

In an animal with the left eye removed this follows as a result of illuminating the specimen laterally from any point to the right of the sagittal plane of the eye. Now, when light enters the eye from any point in the horizontal plane to the right of the median line, various rhabdomes lying along the center and anterior edge of the pigment-cup may be illuminated (fig. 12, $A, b-d$ ). In the same manner, light which enters the eye from some point in the transverse vertical plane of the eye but to the right of the point directly above, always illuminates some of the rhabdomes lying along the center of the dorsal margin of the pigment-cup (fig. 12, $B, b-d$ ). These results indicate that illumination of the rhabdomes of the center and anterior and vertical edges of the pigment-cup is followed by the animal's turning away from the side containing the eye. The region which causes the animal to turn away from the side containing the eye cannot, however be outlined as definitely as that which causes it to turn in the opposite direction, because in some cases light entering the eye may illuminate certain rhabdomes of both regions. Thus, by referring to figure 12 , it will be seen that light entering the eye between the points $b$ and $c$, although it causes the animal to turn away from the side containing the eye, illuminates certain rhabdomes of both regions.

The observations recorded above indicate that illumination of the rhabdomes lying along the ventral and posterior edge of the pigment-cup is followed by the animal's turning toward the side containing the eye, while illumination of the remaining rhabdomes, i.e., those of the center and anterior edge, is followed by the animal's turning in the opposite direction (fig. 13). Further evidence that this conception of localized sensory regions in the eye is a correct one will be taken up in the next section. 
2. Reactions to light in specimens with one eye and the posterior half of the other eye removed. In the preceding section it was concluded that there are two localized sensory regions in the eye. If this is true, the animal should lose the reaction which

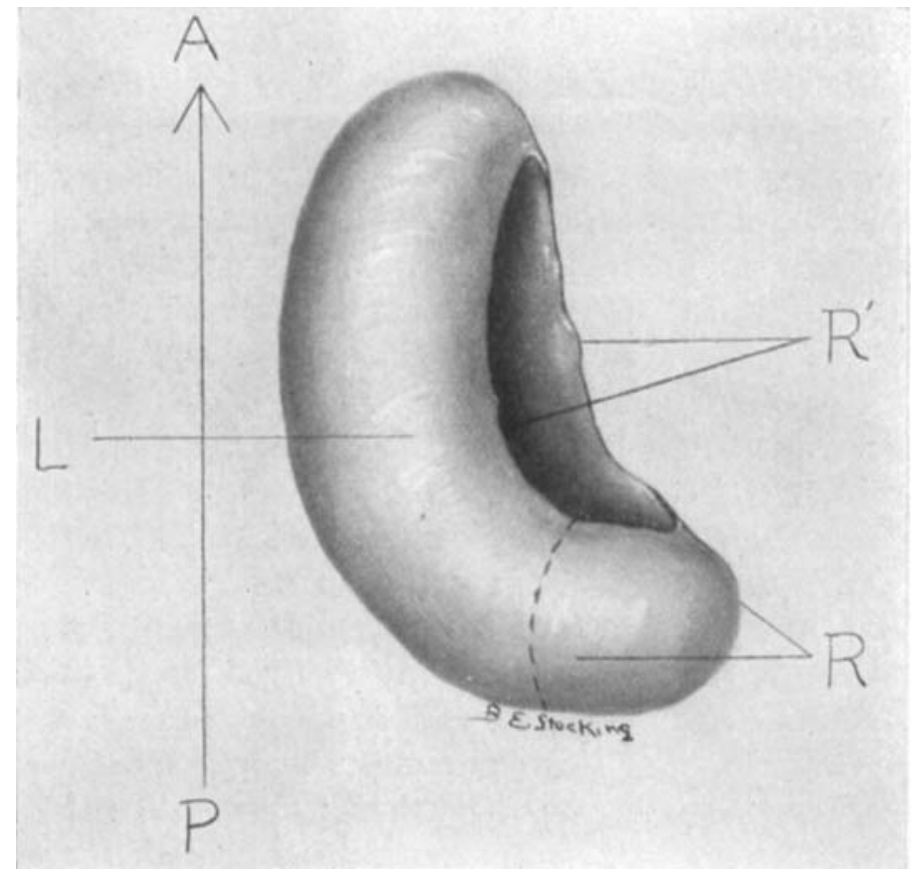

Fig. 13 Drawing representing the shape of the pigment-cup of the right eye and indicating the location of the localized sensory regions. Arrow indicates longitudinal axis; $A$, anterior; $P$, posterior. Illumination of those rhabdomes which lie in the posterior part of the eye, $R$, or on the ventral lip, $R^{\prime}$, results in the animal's turning toward the side containing the cye, viz., the right. Illumination of the rhabdomes which lie in any other part of the pigment cup, $L$, results in the animal's turning in the opposite direction, viz., away from the side containing the eye or the left.

is supposed to result from the stimulation of either of these regions if it is removed. It was found, by very careful manipulation, that the posterior half of an eye could be removed leaving the anterior half uninjured-or at least, functional. After such operations each animal was allowed approximately twenty-four 
hours to recover. After each experiment the specimen was fixed and sectioned. In the majority of cases reconstructions were made of the portion of the eye that remained in the animal. As would be expected from the delicate nature of these operations, a great number of animals were discarded because of some injury, either to the portion of the eye which remained in the animal or to the surrounding tissues. In order to complete eight successful experiments, approximately fifty animals were operated on.

As previously stated, an animal with one eye removed when illuminated directly from in front or slightly from the blind side turns toward the stimulated side. It was concluded that this reaction is due to the stimulation of the rhabdomes covering the posterior-median section of the eye-cup. Now, if this conclusion is correct, the removal of the posterior region of the eyecup should cause the animal to lose this reaction when illuminated from directly in front.

The reactions of eight individuals with the left eye and the posterior half of the right eye removed were studied when illuminated with a horizontal beam coming from directly in front. In all of these the reactions were essentially as follows: The animal generally moved from 1 to $5 \mathrm{~mm}$. directly toward the light at a greatly retarded rate, then it began to wander either to the right or left (fig. 14, $A$ ). Observations indicate that such specimens turned toward the side containing the eye as often as from it. If the animal turned toward the side possessing part of an eye (in this case the right side), it eventually proceeded in an irregular course away from the light (fig. 14, D). There was never any evidence of orientation. If, however, the animal turned toward the 'blind' side (in this case the left side), the animal exhibited no marked reaction until the rays of light illuminated the eye laterally. When this took place the specimen oriented by turning directly from the light until it was fairly accurately oriented (fig. 14, B). It then proceeded in a fairly direct course until a 'wandering reflex' carried it out of the path of orientation.

If the reactions of such an animal are compared with those of a specimen possessing the entire right eye, we see at once that there is a marked contrast. If the Iatter is illuminated from 
directly in front, it turns sharply to the right, i.e., toward the normal side. If, however, the posterior region of the right eye is removed, the animal no longer shows this reaction following such illumination. Instead, such specimens proceed in general

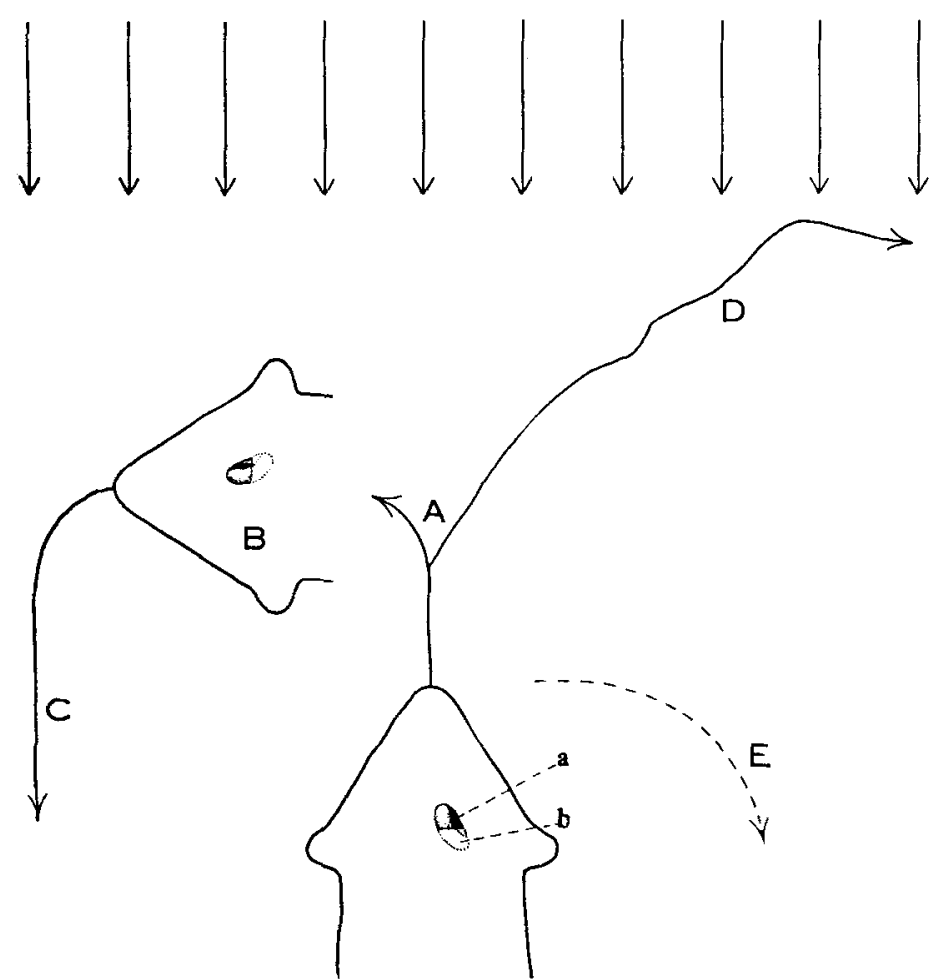

Fig. 14 Diagram representing reactions of a specimen, possessing only the anterior half of the right eye, to a horizontal beam of light coming from directly in front. Arrows, beam of light; $a$, portion of eye remaining; $b$, portion of eye removed. If specimen turns to the left at $A$ and assumes position $B$, it orients by followirg the path $C$. If, however, it turns to the right, it follows an indefinite path, as, for example, $D . E$ represents the path the specimen would have followed had it possessed the entire right eye.

for a short distance directly toward the light, and then turn either to the right or left. In other words, when observed under the effect of illumination from directly in front of the animal, removal of the posterior portion of the eye causes the animal to lose the reaction which ordinarily follows the illumination of this region. 
These results lend very strong support to the conclusions reached in the section dealing with the localization of sensory regions in the eye. In fact, they practically prove the conclusions in regard to one region of the eye.

As an argument against the conclusions set forth above, it might be asked if the removal of the posterior region of the eye has not injured the remainder of the organ to such an extent that we are really dealing with an animal that has no eyes at all. In answer to this question it can be said, 1) the sections of such animals reveal no indication of any injury to the remaining rhabdomes and, 2) the remainder of the rhabdomes are still functional. By referring to the description of the reactions of such animals, it is very evident that the last statement is correct, for it will be remembered that if the animal wanders away from the side containing part of the eye, it sharply and accurately orients as soon as the light illuminates the eye from a lateral position. The only plausible explanation of this is that the reaction follows from an illumination of the rhabdomes in the center of the pigment-cup, or, in other words, that removing the posterior portion of the eye did not injure the capacity of the remainder to function.

3. Reactions to light in specimens with one eye and the anterior half of the other eye removed. The attempt was made to carry out experiments similar to those described in the preceding section, using, however, specimens possessing only the posterior half of one eye instead of the anterior half.

All specimens with one eye and the anterior half of the other (remaining eye) removed react precisely as do specimens with both eyes removed. Under no circumstances is illumination of the part of the eye remaining in the animal followed by orientation as was the case in the animals with the posterior half of the eye removed. The results, at first, seemed rather puzzling, but it can be seen by referring to the section on the structure of the eye that the nerve processes from all of the rhabdomes leave the eye from the anterior edge, and histological examination showed that all of these were cut in removing the anterior half. Removal of the posterior half of the eye, on the other hand, did not injure these fibers. 


\section{Localization of photic stimulation}

Considerable evidence has been noted indicating that the rhabdomes of the eye of Planaria maculata are arranged in two localized sensory regions. If this be actually true, it is obvious that there must be some localizing device whereby light from one direction will stimulate one of these regions and yet not stimulate the other. Otherwise, a general illumination of the eye would result in the stimulation of all the rhabdomes, some of which cause the animal to turn in one direction and others in an opposite direction.

1. Mechanism of localization of photic stimulation. In a paper referred to several times in the preceding pages, Hesse ('97) advances the theory, without experimental evidence, that the pigment of the turbellarian eye acts as a localizer of photic stimulation. This he illustrates very clearly by means of a series of diagrams reproduced in figure 15 .

He maintains that although light can enter the pigment-cup from different angles, it illuminates different portions of the interior from each angle. As he points out, in forms in which there is only one retinula, this would simply result in the illumination of different parts of the same retinula. In forms, however, whose eyes contain numerous retinulae, this mechanism would result in the illumination of different sets of retinulae.

Many of the results presented in the preceding pages are in harmony with Hesse's interesting theory which contains the most valuable suggestion yet made concerning the function of the pigment in flatworm eyes. Some of the results obtained in our work are, however, not in harmony with this theory.

The experiments which we have described dealing with the reactions to light in forms with one eye and the posterior part of the other removed bear directly on the question as to whether or not the pigment acts as a localizer of photic stimulation as Hesse maintains. It will be remembered that such forms when illuminated laterally on the side containing the anterior part of the eye turn directly away from the light and proceed in a more or less direct path, as is the case with normal specimens and specimens with one eye (fig. 14, B). 
The turning in all of these cases follows the illumination of the rhabdomes lying in the center of the pigment-cup (fig. 16, $A$ and $C, x)$. After specimens with normal eyes, either one or two, are oriented, the rhabdomes, owing to the shadow cast by the pigment-cup, are no longer illuminated (fig. 16, B). But in specimens with the posterior portion of the eyes removed, the
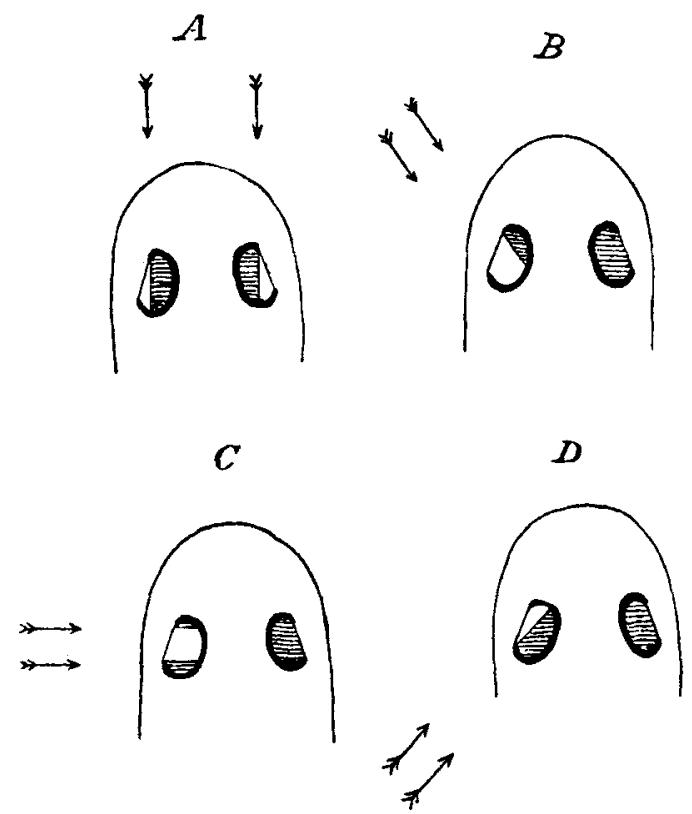

Fig. 15 Different illumination of the planarian eye with light coming from different directions. The optic cups (pigment-cups) are drawn too large in proportion to the head. The arrows indicate the direction of the light; the portions of the interior of the cup which are not illuminated are shaded (after Hesse, '97, p. 575).

rhabdomes are quite as fully exposed to the light after they are oriented as when they are laterally illuminated (fig. 16, $C$ and $D$ ).

The results indicate very plainly that stimulation follows the illumination of the rhabdomes of the center of the pigment-cup only when the light strikes the rhabdomes from a lateral direction, not when it strikes them from behind, as it does in the oriented specimens with the posterior portion of the eyes removed. This seems to show that it is not necessary for the pigment to act as 
a localizer of photic stimulation as maintained by Hesse. The localizing mechanism appears to be contained in some manner in the rhabdomes themselves.

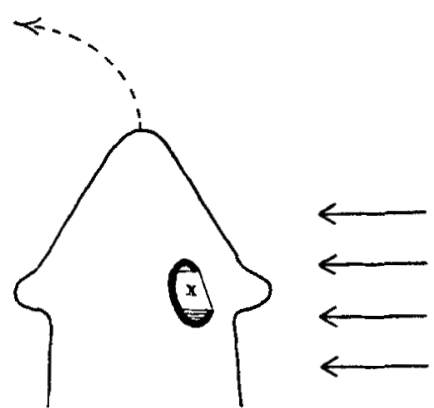

A

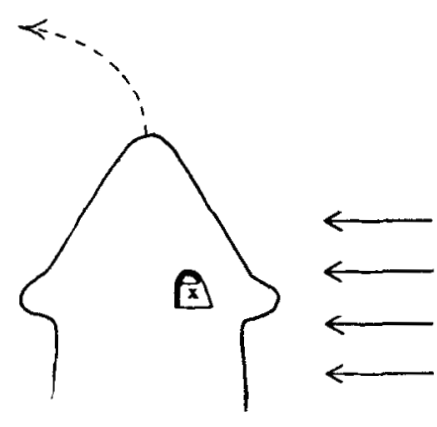

C

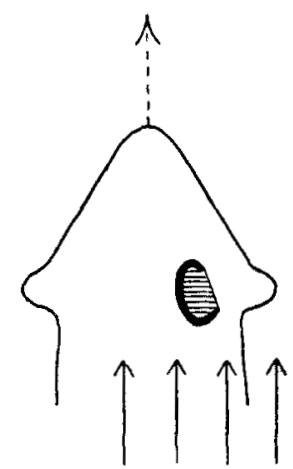

B

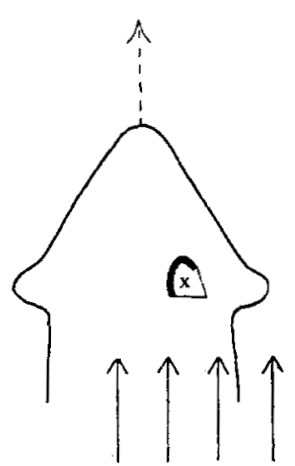

D

Fig. 16 Illumination of eye with light coming from different directions. $A$ and $B$, animal possessing entire right eye; $C$ and $D$, animal possessing anterior half of right eye. Arrows indicate the direction of rays of light; broken lines indicate path of specimen; $x$, position of rhabdomes which are illuminated. Animal $D$ proceeds directly away from the light although the same rhabdomes are being illuminated as in $C$ when it turned sharply to the left.

The idea suggested itself to the author that the above conclusion might not be valid because of the possibility that in removing the posterior half of the eye the pigment might be 
carried by the knife and spread over the posterior surface, and that this might make an effective light screen just as in the case of the normal animal. Histological examination of such specimens showed this idea to be erroneous. A few granules are always displaced in making an incision, but these are very much scattered and obstruct the passage of light very little, if at all. Again, the body of the animal might act as a shading mechanism. This, however, was shown not to be true as the same results can be obtained when the source of illumination is lifted slightly above the horizontal plane, in which case the light does not pass through any more of the tissue of the animal's body than in normal lateral illumination. "We are consequently forced to accept the conclusion that light entering the eye from behind does not stimulate the rhabdomes as it does when it enters from the side. That is, that light striking certain rhabdomes from the direction indicated by the arrow $a$ (fig. 17) is followed by a definite turning of the animal, whereas no such turning results when light strikes the same rhabdomes from the direction indicated by the arrow $b$. None of the experimental work has offered any explanation of this phenomenon. The structure of the retinula and its relation to the pigment-cup, however, offer two possible explanations.

In the living condition in Prorhynchus applanatus, according to Kepner and Taliaferro ('16), the middle region of the retinula or the region which corresponds to the ellipsoid of the vertebrates is the most refractive portion of the retinula. The same holds true for Planaria maculata after fixation. This region, because of its position, contour, and refractive index, must have some effect on the rays of light as they pass down the longitudinal axis of the retinula to strike the rhabdome (fig. 17,a). It occurs to one that possibly this region serves as a crude lens to concentrate the rays of light upon the sensitive rhabdome and that photic stimulation depends upon this. If this is true, photic stimulation could not be set up in a given rhabdome unless the light struck the rhabdome approximately parallel to its longitudinal axis. Not only would the light have to strike the rhabdome approximately parallel with its longitudinal axis, but it 
would have to pass through the retinula in a distal direction. Otherwise the light would not be affected by the middle region.

If the above suggestion is correct, the pigment would play no part in the localization of photic stimulation in the individual retinulae. We might, however, conceive that the middle region has no effect on photic stimulation, but that the rhabdome is itself so constructed that only light passing along its longitudinal

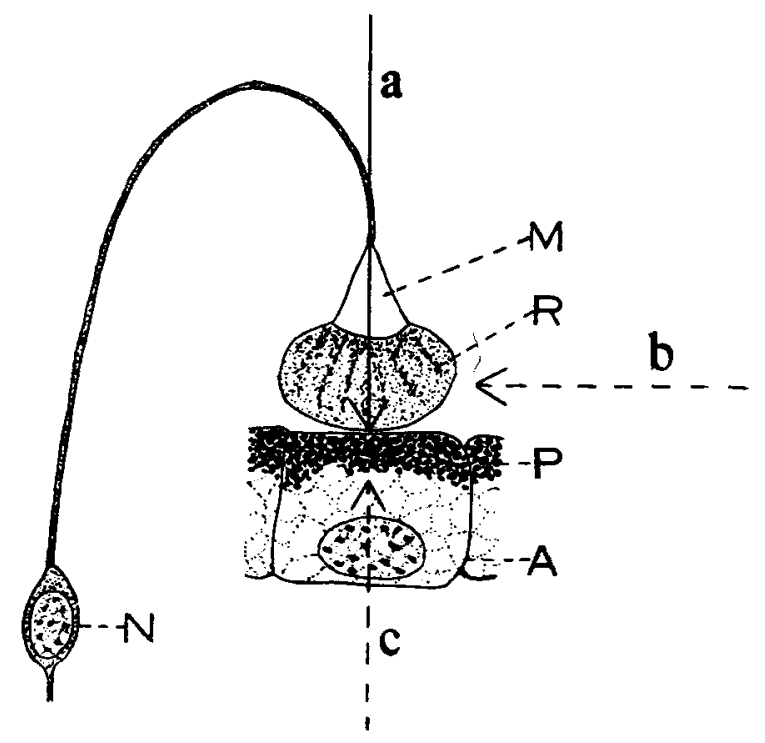

Fig. 17 Diagram representing the relation between structure and photic stimulation in the individual retinula. $A$, one of the accessory cells which form the pigment-cup; $M$, middle region of the retinula; $N$, nucleus of retinula; $R$, sensory rhabdome. Light striking the rhabdome parallel to the axis $a$ results in stimulation. Light from the direction $b$ or $c$ does not result in stimulation.

axis sets up stimulation. If this is true, light from either direction as long as it is parallel to the longitudinal axis might cause stimulation. The pigment, then, might serve to localize photic stimulation in that it would prevent light passing through the rhabdome in a proximal direction and allow light from the opposite direction to strike the rhabdome. Thus, in figure 17 , the pigment is so placed that light along the arrow $c$ cannot strike the rhabdome. While this suggestion ascribes a certain limited localizing function 
to the pigment, it is evident that it does not ascribe to the pigment the entire function of the localization of photic stimulation as is done by Hesse ('97).

2. Localization of photic stimulation in relation to the structure of the eye. If we are correct in the assumption that light must penetrate a given rhabdome along its longitudinal axis in order to stimulate it, then the structure of the eye should be such that whenever light enters it, under normal conditions, the longitudinal axes of some of the illuminated rhabdomes will be parallel to the stimulating rays of light. Let us consider this problem.

The best way to describe the relation of the axis of the light rays entering the eye to the axes of the rhabdomes is to consider the actual condition of affairs when the eye is illuminated from each of several different directions. This is represented in figure 18. By referring to this figure the following may be seen: Light which strikes the eye from directly in front of the animal illuminates those rhabdomes which lie on the outer posterior margin of the pigment-cup, and the longitudinal axes of all of these rhabdomes are directed approximately parallel to the rays of light (fig. 18, $A, a, 8$ and 9). The same holds true for light entering the eye from an oblique posterior direction (fig. 18, $B, d, 1$ ), and, approximately, for lateral illumination (fig. 18, $A, b, 2-6)$. When the light comes obliquely from in front of the animal, however, the light rays strike certain rhabdomes parallel with their longitudinal axes (fig. 18, $B, c, 7$ ) and other rhabdomes at various angles to their longitudinal axes (fig. 18, $B, c, 5,6,8,9)$.

The same is true for the rhabdomes when the light enters the eye from different points in the transverse vertical plane. Light which enters the eye from directly above (fig. 18, $C, a, 8$ ) and obliquely below (fig. 18, $D, d, 1$ ) strikes all of the rhabdomes in both cases parallel to their longitudinal axes. Light from obliquely above (fig. $18, D, c, 4-8$ ) and, to a less extent, light from the side (fig. 18, $C, b, 2-4$ ) passes along the longitudinal axis of certain rhabdomes and not of others.

This seems to indicate that the structure of the eye is such that if light from any given direction enters the eye, it illuminates 
the rhabdomes confined to a definite area; that, in such areas, there is always a large proportion of the rhabdomes which have their longitudinal axes parallel with the rays of light; and that, in a number of cases, the longitudinal axes of all of the rhabdomes in the illuminated area are nearly parallel with the rays of light.

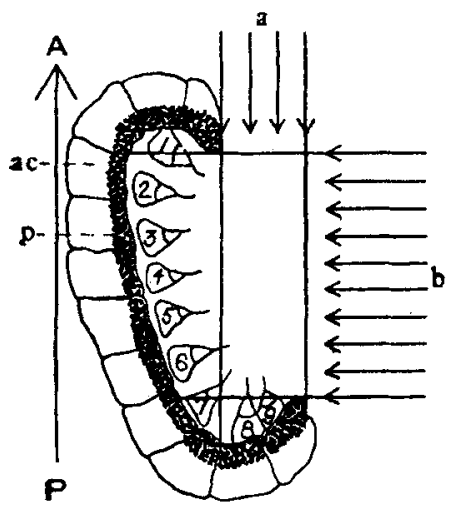

A

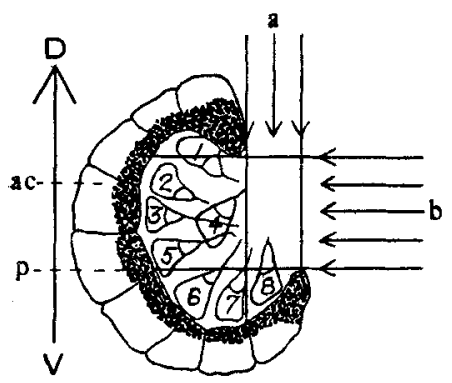

C

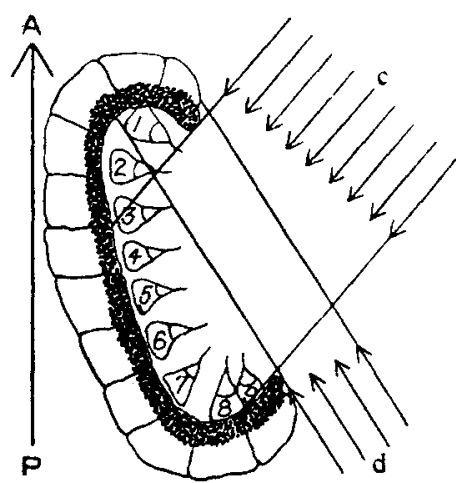

B

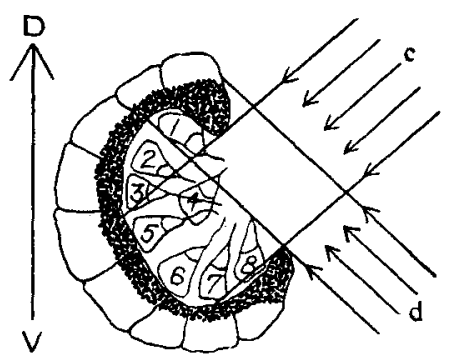

D

Fig. 18 Diagram representing the relation of the axis of photic stimulation to the axes of the various rhabdomes when the eye is illuminated from different directions. The diagrams are made from camera-lucida drawings of sections. $A$ and $B$, frontal sections of the eye; $C$ and $D$, transverse sections of the eye; $A-P$, antero-posterior line; $D-V$, dorsoventral line; $a, b, c, d$, arrows indicating the different beams of light; $a c$, accessory cells; $p$, pigment-cup; $1-9$, rhabdomes. 
These observations strongly support the assumption that if light strikes a rhabdome parallel with its longitudinal axis stimulation results; whereas, if light does not strike a rhabdome along this axis stimulation does not follow. This will explain why it is not necessary for the pigment-cup to act as a localizer of photic stimulation. The latter is localized not by the pigmentcup, but by the position of the longitudinal axes of the various rhabdomes.

\section{NATURE OF THE STIMULUS DURING ORIENTATION}

At the present time there are two chief theories advanced to account for the orientation of organisms to light - the continuousaction theory and the change-of-intensity theory. The literature bearing on these two theories is so extensive that we shall limit the present review to a very brief outline.

Loeb, who is the chief upholder of the continuous-action theory, maintains that an organism orients to light because of unequal chemical changes induced by the light in symmetrically placed photoreceptors; that effects of these chemical changes are transmitted eventually to the locomotor organs, thus producing unequal 'tension or energy production' in the musculature of the two sides, and that this results in a turning of the organism. According to him, after the organism has become oriented, the light produces equal chemical changes in the photoreceptors and the organism proceeds directly toward or away from the light owing to continuous and equal action of the light on symmetrically located photoreceptors.

In reference to his theory, he says ('16, pp. 258-259):

The reader will perceive that according to the writer's theory two agencies are to be considered in these reactions: first, the symmetrical arrangement of the photosensitive and the contractile organs, and, second, the relative masses of the photo-chemical reaction products produced in both retinae or photosensitive organs at the same time. If a positively heliotropic animal is struck by light from one side, the effect on tension or energy production of muscles connected with the eye will be such that an automatic turning of the head and the whole animal towards the source of light takes place; as soon as both eyes are illuminated equally the photochemical reaction velocity will be the 
same in both eyes, the symmetrical muscles of the body will work equally, and the animal will continue to move in this direction. In the case of the negatively heliotropic animal the picture is the same except that if only one eye is illuminated the muscles connected with this eye will work less energetically

Loeb holds, moreover, that the orienting stimulus in organisms, both animals and plants, is dependent upon the actual amount of stimulating energy received by the photoreceptors in accord with the Bunsen-Roscoe law.

Opposed to the continuous-action theory, is the change-ofintensity theory, supported chiefly by the works of Jennings and Mast. According to this theory, the orienting stimulus is not dependent upon the actual amount of energy received by the photoreceptors, but to time-rate-of-change of the stimulating energy. Once an organism is oriented to light, it is supposed to receive no orienting stimulus until it leaves the path or axis of orientation.

The great body of evidence, especially in the unicellular forms, tends to favor the change-of-intensity theory. Mast has discussed this evidence fully in Light and the Behavior of Organisms ('11) and in numerous recent papers (Mast, '16). In certain seedlings, however, Blaauw ('08), Fröschel ('08), Arisz ('11), and Clark ('13) have demonstrated that within certain limits orientation to light is dependent upon the actual amount of energy received. This is in accord with the continuous-action theory. Likewise, Mast ('11, p. 163) and Loeb and Ewald ('14) have come to practically the same conclusion in regard to the orientation of the sessile polyp Eudendrium.

The chief questions that are at issue between these two theories are: 1) Does stimulation during orientation depend upon the continuous action of light or to time-rate of change in the intensity? 2) Does the same stimulus that causes orientation continue to act after orientation? 3) Is it essential that the photoreceptors which receive the orienting stimulus be placed symmetrically?

While this work was not taken up with any especial reference to these questions, some of the observations bear directly upon them. In regard to the first question, while some of the evidence favors the change-of-intensity theory, there is no direct evidence 
that stimulation during orientation is due necessarily to either the actual amount of energy received or to the time-rate of change in intensity. In regard to the second and third questions, however, we can draw definite conclusions.

In the first place, as has been noted (p. 74), when an animal is proceeding away from the source of illumination, it tends to wander to the right or left (wandering reflex). When the animal has thus turned its head laterally to the extent that the rays of light enter the mouth of the pigment cup, it re-orients. This behavior strongly suggests that once the animal is oriented it receives no orienting stimulation until it leaves the path of orientation. In the second place, it was shown above (p. 95), under the experiments designed to map the regions of the eye, that no stimulation is received (or more exactly no reaction follows) as long as the pigment-cup is between the source of illumination and the rhabdomes. Now, an examination of the relative positions of the eyes shows very clearly that once an animal is oriented and is proceeding away from the light, no light can strike the rhabdomes unless it does pass through the pigment. From these observations we must conclude that when a planarian is moving away from the light the pigment-cup effectively shades the sensory portion of the eye. Therefore, as there is no continuous illumination of the sensory organs involved in orientation, there can be no continuous stimulation of these organs.

The fact that specimens with one eye removed orient accurately to light (fig. 9) shows clearly that the symmetrical arrangement of the two eyes is not essential for orientation. The extent of turning is probably reflexly determined by the portion of the eye stimulated and is independent of the duration of the stimulation.

It may, therefore, be concluded that, while our evidence is not conclusive in regard to the nature of the stimulus, orientation in Planaria maculata is not in accord with the 'continuous-action' theory as defined by Loeb. 


\section{GENERAL SUMMARY}

1. The eye of Planaria maculata is a typical turbellarian eye, consisting of two types of cells-the accessory cells forming the pigment-cup and the sensory cells or retinulae.

2. Each retinula consists of three regions--the nucleus-bearing region, the middle region, and the rhabdome, which show a striking resemblance to the three regions of the veretebrate retinula, viz., the myoid, the ellipsoid, and the rhabdome.

3. Planaria maculata is negative to light and orients accurately to a horizontal beam of light.

4. Orientation is, under certain conditions, direct; the animals may turn directly away from the source of light without preliminary trial movements. Trial movements are, however, at times functional in the process of orientation.

5. The location of the bending of the body, when the head is turned away from the light, depends upon the intensity of the light-the higher the intensity of illumination, the more posteriorly the point of bending is located. It is, however, never located farther back than the pharynx.

6. If the intensity is high enough (or possibly continued long enough) to cause the bending to take place in the region of the pharynx, the animal no longer bends directly away from the light, but first toward and then away.

7. During the reactions of animals to a horizontal beam of light, two marked motor reflexes occur, viz., the twisting reflex and the wandering reflex. These reflexes are defined on pages 74 and 75 .

8. Specimens with both eyes removed do not orient in directive illumination as do normal specimens. They move, however, in general, away from the light.

9. Removal of both eyes does not appreciably affect the rate of locomotion in either directive or non-directive illumination.

10. Removal of the anterior end, on the contrary, greatly retards the rate of locomotion in both directive and non-directive illumination.

11. Specimens with one eye removed show no indication of circus movements or other abnormal motor activities. 
12. Specimens with one eye removed orient accurately to light, when illuminated on the normal side, by turning directly away from the source of light.

13. Such specimens do not orient to light when illuminated on the 'blind' side unless the head is moved so that light enters the remaining eye. If, however, the head is moved so that light enters the remaining eye (wandering and twisting reflex), accurate orientation may follow.

14. The rhabdomes in the eye are arranged in two localized sensory regions; illumination of the rhabdomes of the posterior and ventral edge of the pigment-cup is followed by the animal's turning toward the side containing the eye, while illumination of the remaining rhabdomes is followed by the animal's turning in the opposite direction.

15. Specimens possessing only the anterior portion of one eye, when illuminated from in front, do not turn sharply toward the side containing the eye, as do specimens possessing one entire eye. The loss of this reaction in such specimens is probably due to the loss of the rhabdomes situated on the posterior margin of the pigment-cup.

16. Removal of the posterior portion of the eye does not impair the capacity of the remainder of the eye to function in a normal manner.

17. Specimens possessing only the posterior portion of one eye react to light as do specimens with both eyes removed. Histological examination of such specimens shows, however, that removal of the anterior portion of the eye severs the connection between the remaining rhabdomes and the 'brain.'

18. The observed reactions in Planaria can be explained without assuming that the pigment-cup acts as a localizer of photic stimulation as suggested by Hesse ('97). It is possible, however, that the pigment has a limited localizing function in the individual retinula.

19. Light must strike a given rhabdome parallel with its longitudinal axis in order to cause stimulation of the rhabdome. Thus the position of the longitudinal axis of the rhabdomes results in a localization of photic stimulation. 
20. It is possible to explain this localization of photic stimulation in the individual retinula: 1) by supposing that the highly refractive middle region of the retinula acts as a crude lens to concentrate the rays of light on the rhabdome; or 2) by assuming a certain structure of the rhabdomes coupled with the shading action of the pigment-cup. This last assumption ascribes a limited localizing function to the pigment, but it does not ascribe to the pigment the entire function of the localization of photic stimulation as is done by Hesse (page 106).

21. Correlated with the assumption that light must penetrate a given rhabdome parallel with its longitudinal axis in order to cause stimulation, we find that light in entering the pigmentcup from any given direction illuminates the rhabdomes confined to a definite area and that a large proportion of the rhabdomes in such areas always have their longitudinal axes directed parallel to the stimulating rays of light and, in the case of light from certain directions, all of the rhabdomes which are illuminated have their longitudinal axes so directed.

22. Once an animal is oriented in a horizontal beam of light, it receives no orienting stimulation until it leaves the path or axis of orientation.

23. Orientation to light is not necessarily dependent upon the symmetrical arrangement of the photoreceptors.

\section{BIBLIOGRAPHY}

Arey, L. B 1916 Changes in the rod-visual cells of the frog due to the action of light. Jour. Comp. Neur. vol. 26, pp. 429-442.

Arisz, W. H. 1911 On the connection between stimulus and effect in phototropic curvatures of seedlings of Avena sativa. Kon. Ak. Wet. Amsterdam. Proc., pp. 1022-1031.

Bardeen, C. R. 1901 On the physiology of the Planaria maculata with especial reference to the phenomena of regeneration. Am. Jour. Physiol., vol. 5, pp. 1-55.

Blasuw, A. H. 1908 The intensity of light and the length of illumination in the phototropic curvature in seedlings of Arvena sativa. Kon. Ak. Wet. Amsterdam. Proc.

Börmıg, L. 1890 Untersuchungen über rhabdocöle Turbellarien. II. Plagiostomia and Cylindrostomia Graff. Zeit. f. wiss. Zool., Bd. 51, S. 167479.

Boring, E. G. 1912 Note on the negative reaction under light adaptation in the planarian. Jour. Animal Behav., vol. 2, pp. 229-248. 
Clark, O. L. 1913 Über negativen Phototropismus bei Avena sativa. Botan. Zeitschr, Bd. 5, S. 737-770.

Curmis, W. C. 1902 The life history, the normal fission and the reproductive organs of Planaria maculata. Proc. Boston Soc. Nat. Hist., vol. 30, pp. 515-559.

Fröscher, P. 1908 Untersuchungen über die heliotropische Präsentationszeit. Sitz.-Ber. math.-naturw. K1. Akad. Wiss., Wien, Bd. 117, Abt. 1, S. 235-256.

Hessw, R. 1897 Untersuchungen über die Organe der Lichtempfindung bei niederen Thieren. II. Die Augen der Plathelminthen, insonderheit der tricladen Turbellarien. Zeit. f. wiss. Zool., Bd. 62, S. 527-582.

JänICHes, E. 1896 Beiträge zur Kenntnis des Turbellarienauges. Zeit. f. wiss. Zool., Bd. 62, S. 250-288

Kepner, W. A., ANd Foshee, A. M. 1917 Effects of light and darkness on the eye of Prorhynchus applanatis Kennel. Jour. Exp. Zoöl., vol. 23, pp. 519-531.

Kepner, W. A., and Lawrence, J. S. 1918 The eye of Polycystis goettei (Bresslau). Jour. Exp. Zool., vol. 30, pp. 465-473.

Kepner, W. A., and Taliaferro, W. H. 1916 Organs of special sense of Prorhynchus applanatus Kennel. Jour. Morph., vol. 27, pp. 163-177.

Leidy, J. 1847 Descriptions of two new species of Planaria. Proc. Acad. Nat. Sci. (Phila.), vol. 3, pp. 251-252.

LiLlie, F. R. 1901 Notes on regeneration and regulation in planarians. Am. Jour. Physiol., vol. 6, pp. 129-141.

Loes, J. 1893, Uber künstliche Umwandlung positiv heliotropischer Thiere in negativ heliotropische und umgekehrt. Arch. f. d. ges. Physiol., Bd. 54, S. 81-107.

1894 Beiträge zur Gehirnphysiologie der Würmer. Arch. f. d. ges. Physiol., Bd. 56, S. 247-269.

1916 The organism as a whole. New York, $x+379$ pp.

Loeb, J., and Ewald, W. F. 1914 Uber die Gültigkeit des Bunsen-Roscoeschen Gesetzes für die heliotropische Erscheinung bei Tieren. Zentb. f. Physiol., Bd. 27, S. 1165-1168.

Mast, S. O. 1910 Preliminary report on reactions to light in marine Turbellaria. Carnegie Instit. Year Book, vol. 9, pp. 131-133.

1911 Light and the behavior of organisms. New York, xi $+410 \mathrm{pp}$. 1916 The process of orientation in the colonial organism, Gonium pectorale, and a study of the structure and function of the eyespot. Jour. Exp. Zoöl., vol. 20, pp. 1-17.

Parker, G. H., AND BuRnett, F. L. 1900 The reactions of planarians, with and without eyes, to light. Am. Jour. Physiol., vol. 4, pp. 373-385.

PearL, R. 1903 The movements and reactions of fresh-water planarians: A study of animal behaviour. Quart. Jour. Micro. Sci., vol. 46, pp. 509-714.

Schmid, A. T. 1902 Zur Kenntnis der Tricladenaugen und der Anatomie von Polycladus gayi. Zeit. f. wiss. Zool., Bd. 72, S. 545-564.

Sherrington, C. S. 1898 Cutaneous sensations. Text-book of physiology edited by E. A. Schäfer, vol. 2, pp. 920-1001. 
Taliaferro, W. H. 1917 Orientation to light in Planaria n. sp. and the function of the eyes. Anat. Rec., vol. 11, pp. 524-526.

WaLter, H. E. 1907 The reactions of planarians to light. Jour. Exp. Zoöl., vol. 5 , pp. $35-162$.

Woopworth, W. McM. 1897 Contributions to the morphology of the Turbellaria. II. On some Turbellaria from Illinois. Bull. Mus. Comp. Zoöl. Harvard Coll., vol. 31, pp. 1-16. 